\title{
Charles-Marie de La Condamine, Voltaire oder die Dialektik der Aufklärung
}

Das 18. Jahrhundert bot viele Möglichkeiten, sich von Europa aus mit anderen Teilen unseres Planeten zu beschäftigen. Die im Jahrhundert der Aufklärung so beliebten Reiseberichte ${ }^{1}$ europäischer Reisender besitzen den unschätzbaren Vorteil, gleichsam implizit die Aufklärung als einen grundlegenden Aspekt der Beziehungen zwischen unterschiedlichen Welten darzustellen, auch wenn in der Regel das aufgeklärte Subjekt Europäer ist und dessen Forschungsobjekte Bewohner der Welten außerhalb Europas sind, die es im besten Falle aufzuklären gilt. Insofern verkörpern sie in hohem Maße das Selbstbild der Europäer als allen Völkern an Wissen und Wissenschaften weit überlegenen Vertretern eines Kontinents, der zu Recht über Wohl und Wehe weiter Gebiete unseres Planeten bestimmte und vor allem in der zweiten Jahrhunderthälfte auf Grund großer materieller Überlegenheit seine kolonialen Ansprüche noch auszuweiten versuchte. Die unterschiedlichsten Teile der Erde werden vermessen und miteinander in Beziehung gesetzt, wodurch sich ein Spiel von Selbst- und Fremdbild, von Auto- und Heterostereotypen ergibt, das uns sehr viel über die Leitlinien einer Konvivenz im 18. Jahrhundert mitteilen kann.

Europa vermaß die Erde und machte damit den Rest des Planeten zum Gegenstand seines unstillbaren und zumeist interessegeleiteten Wissensdurstes. Selbst das vom französischen ,Zentrum‘ der Aufklärung so gescholtene Spanien erforschte unentwegt die von ihm in Besitz genommenen Kolonialgebiete und rüstete im Verlauf der gesamten Kolonialzeit mehrere hundert Expeditionen aus, ${ }^{2}$ um seine eigenen wie angrenzende Territorien $\mathrm{zu}$ erkunden. Freilich war es mit der Weitergabe dieser Informationen höhst zurückhaltend, stellten jene Forschungsergebnisse doch Staatsgeheimnisse dar, die man an andere mögliche Kolonialmächte nicht weiterzugeben gewillt war. Von diesen Reisen im Interesse von Kolonialmächten kann man jene Forschungsreisen unterscheiden, die überwiegend einem wissenschaftlichen Interesse dienten und deren Resultate zur Veröffentlichung bestimmt waren, wollte man dadurch doch den Fortschritt der ,Menschheit' respektive Europas befördern und das auf dem Alten Kontinent gesammelte Weltwissen vergrößern.

1 Vgl. den ersten Band der Reihe „Aula“, Ette, Ottmar: ReiseSchreiben. Potsdamer Vorlesungen zur Reiseliteratur. Berlin - Boston: Walter de Gruyter 2020.

2 Vgl. Fendler, Ute: Kolonialisierung als frühe Globalisierung? Hispanoamerika in Reiseberichten des 18. Jahrhunderts. In: Pinheiro, Teresa / Ueckmann, Natascha (Hg.): Globalisierung avant la lettre. Reiseliteratur vom 16. bis 21. Jahrhundert. München: Lit Verlag 2005, S. 75-90.

2 Open Access. ( 2021 Ottmar Ette, publiziert von De Gruyter. (c) BY-NC-ND Dieses Werk ist lizenziert unter einer Creative Commons Namensnennung - Nicht-kommerziell - Keine Bearbeitung 4.0 International Lizenz. https://doi.org/10.1515/9783110703467-008 
Mit der in der ersten Hälfte des 18. Jahrhunderts durchgeführten Reise von Charles-Marie de La Condamine und anderer Teilnehmer einer Expedition, ${ }^{3}$ die von der französischen Académie des Sciences ausgesandt die spanischen Kolonien in Amerika zum Ziel hatte, beginnt in gewisser Weise eine neue Etappe innerhalb der Reiseliteratur, vor allem aber der Auseinandersetzung Europas mit Amerika. Denn es sind nun nicht mehr iberische Konquistadoren, Missionare oder Abenteurer, die diese Reise in die Neue Welt spült, sondern die akademisch renommierten Boten eines wissenschaftlichen Interesses und wissenschaftlicher Fähigkeiten, zu deren Ziel im 18. Jahrhundert der amerikanische Kontinent in steigendem Maße wurde. Denn für viele Wissenschaftler des 18. und des beginnenden 19. Jahrhunderts wurde Amerika - und insbesondere das tropische Amerika - zu einem wahren Eldorado des Wissens und zugleich der ,Wunder', die man nicht nur zu beschreiben, sondern weit mehr noch zu erklären suchte. Amerika stand damit freilich noch immer im Zeichen des „merveilleux“, des Wundersdamen und Wunderbaren. Denn diese Neue Welt war alles andere als zufriedenstellend untersucht und harrte noch jener Beschreibungen, die einen modernen Blick - und den Blick der Moderne - auf die Amerikas eröffnen und damit die moderne Weltsicht kreieren sollten.

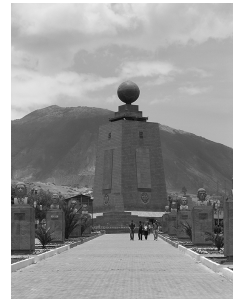

Abb. 20: Äquatormonument „Mitad del Mundo“ in San Antonio de Pichincha bei Quito.

Wie präsent diese Reise aus der Sattelzeit der Moderne noch heute ist, erlebt man in Quito, der Hauptstadt des heutigen Ecuador. Dort kann man einen Bus zu einem wunderschönen Ort wenige Kilometer nördlich des Zentrums der Andenstadt nehmen, von wo aus man nicht nur einen herrlichen Blick über die Andenkette hat, sondern wo der Äquator die Kordillere im heute danach benannten Ecuador schneidet. Wo einst die französischen Forscher im Verbund mit spanischen Offizieren und kolonialspanischen Gelehrten ihre Messungen

3 Vgl. das La Condamine gewidmete Kapitel in Ette, Ottmar: ReiseSchreiben. Potsdamer Vorlesungen zur Reiseliteratur, S. 368-395. 
unternahmen, da treffen Sie heute auf einen gewaltigen Monumentalbau. Bemerkenswert ist noch immer, wie groß auch heute noch die Verehrung für all jene französischen Wissenschaftler ist, die nicht zu Zwecken der Eroberung das damalige Teilgebiet des spanischen Weltreichs bereisten. Denn die französischen Gelehrten kamen als „Académiciens“, als Mitglieder der Französischen Akademie der Wissenschaften, vorsichtig beäugt und kontrolliert von den spanischen Kolonialbehörden, denen sie als potentielle Unruhestifter galten. Doch im Grunde führten die Franzosen nichts Böses im Schilde, sondern versuchten allein, eine wissenschaftliche Frage einer wissenschaftlichen Antwort zuzuführen. Die Frage lautete, ob die Erde so aussieht wie der Globus in Ihrem Kinderzimmer, also eine perfekte Kugel darstellt, oder ob sie an den Polen abgeplattet und am Äquator gleichzeitig ausgebeult ist. Nicht mehr, aber auch nicht weniger war von den französischen Akademikern zu klären.

Sicherlich war dies eine Frage, die nicht nur rein theoretischen Charakter besaß, sondern auch unmittelbare Konsequenzen für die Berechnung von Schiffspositionen auf unserem Planeten haben konnte. Denn das Kartennetz, das Europa seit der berühmten Karte des Juan de la Cosa im Jahr 1500 über die ganze Welt ausgeworfen hatte, musste ständig präzisiert und konkretisiert werden, um bestimmte Navigationsberechnungen noch präziser durchführen zu können. In der Tat wurden im Verlauf des 18. Jahrhunderts die Welt- und Detailkarten immer genauer und näherten sich ihrer modernen Form an, die im Grunde schließlich in vielerlei Hinsicht mit den Kartenwerken Alexander von Humboldts zu Beginn des 19. Jahrhunderts erreicht war. Die von den französischen „Académiciens“ gestellte und von ihnen - wir wir gleich sehen werden auch gelöste Frage schreibt sich ein in die Eroberung des Raumes durch Europa und in die Grundlagen eines wissenschaftlichen Wissens über unsere Erde, das zugleich auch Herrschaftswissen war. Die (durchaus kolonialistisch zu verstehende) Ambivalenz dieses Wissens, das in Europa gesammelt wurde, gilt es stets im Gedächtnis zu behalten, fragt man nach den Zielen und Zwecken europäischer Wissenschaften.

Die wissenschaftliche Frage also, wie die Erde beschaffen sei und ob sie eine Kugelgestalt besitze, ob sie eher elliptisch, abgeplattet oder ausgebuchtet an den Polen beziehungsweise am Äquator sei, war also ein Problem, das durchaus militärpolitisch von Bedeutung sein konnte. Man kann die spanische Krone folglich verstehen, wenn sie die Einreise von französischen Forschern zur Klärung einer wissenschaftlichen Frage erlaubte, diesen zugleich aber eine geostrategisch ausgebildete Überwachung durch spanische Offiziere angedeihen ließ, um keine nationalen Risiken in Kauf nehmen zu müssen. Schließlich hinterließen die Franzosen zur Markierung ihrer Messpositionen auch trigonometrische Punkte, die kunstvoll mit dem Wappen der Könige von Frankreich 
verziert waren, ein auf den ersten Blick eher ornamentales Detail, das später dazu führen sollte, dass diese Punkte von der spanischen Kolonialmacht wieder zerstört wurden.

Die genaue Form der Erde war seit den Anfängen der europäischen Expansion eine offene Frage. Christoph Kolumbus hatte entgegen aller Überlieferungen die Erde nicht mit einer Kugel verglichen - und übrigens auch nicht mit einem Ei, dem sogenannten Ei des Columbus -, sondern mit einer Frucht, genauer einer Birne. Dabei gesellte er dieser Vorstellung zugleich noch einige mittelalterliche Akzente zu, indem er der Birne in etwas krasser MetaphernSprache eine - wie er sich ausdrückte - weibliche Brust aufsetzte, deren Brustspitze sozusagen das Paradies anzeigte. Denn dieses musste ja - ähnlich wie Dantes Läuterungsberg - erhoben und erhaben sein, damit von ihm auch die vier Flüsse des Paradieses herabfließen konnten; eine Vorstellung, die sich noch in den Literaturen des 19. Jahrhunderts immer wieder findet. Vor einem dieser gewaltigen Flüsse glaubte sich Kolumbus ja auch in der Tat im Mündungsbereich des Orinoco, wie später auch die Reisenden am Amazonas die Größe dieses Flusses mit den Paradiesversprechungen der Bibel in einen Zusammenhang brachten. Hatte es nicht etwas Paradiesisches, dass diese Ströme solche Massen an Süßwasser verfrachteten, dass man selbst auf hoher See weit draußen vor dem Mündungsbereichen von Orinoco oder Amazonas Süßwasser im Meer aufnehmen konnte?

Doch Kolumbus war keineswegs der Einzige, der dies schon bei seinen ersten Fahrten in Begleitung des Juan de la Cosa bemerkte. Und er blieb auch nicht der Einzige, der die Erde mit einer Frucht verglich. Denn der erste Globus der Menschheit entstand schon wenige Jahre nach der Kunde von Amerika, und sein Erfinder, Martin Behaim, hatte ihm die Form eines Apfels gegeben, eines Erdapfels also, den sie im Übrigen noch heute im Museum in Nürnberg sehen können. Bei der Frage nach der Gestalt der Erde handelte es sich also um ein Thema, das von Beginn der großen Entdeckungsfahrten an präsent gewesen war.

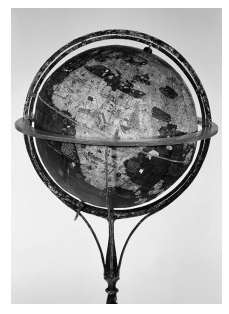

Abb. 21: Martin Behaims „Erdapfel“. 
Sie sehen also: Die Frage nach der genauen Gestalt der Erde, deren Globalität spätestens mit der Reise des Kolumbus und nach ihm der ersten Weltumsegelung des Magalhães oder Magellan eine bewiesene Sache war, bot von Beginn an genügend Stoff für allerlei Theorien und Mutmaßungen, aber auch Träume und Imaginationen. Für die französischen Akademiker war eines wichtig: Der Brite Isaac Newton vertrat die These, dass die Erde ein Ellipsoid sei mit abgeflachten Polen und einem ausgebuchteten Äquatorbereich, dass sie also durchaus nicht so aussähe, wie wir uns dies gerne perfekt ausmalen oder auch die zusätzlich noch genordeten NASA-Bilder von unserem „Lonely Planet“ vorgaukeln. Gegen Newtons These freilich gab es früh und vor allem in Frankreich Widerstand, vor allem durch den Astronomen Cassini. Die Sache wurde zu einem Problem zwischen England und Frankreich, den beiden kommenden Führungsmächten der bevorstehenden zweiten Phase beschleunigter Globalisierung.

Daher entschied sich die französische Académie des Sciences dafür, zwei Expeditionen auszusenden. Eine erste Erkundungsreise sollte unter der Leitung von Maupertuis, den wir als den ersten Präsidenten der Königlich Preußischen Akademie der Wissenschaften zu Berlin kennen, nach Lappland führen. Dies war eine Expedition, die Voltaire - mit dem wir uns gleich noch beschäftigen werden - in einem seiner Contes philosophiques behandelte, wobei er ihr dadurch langanhaltenden literarischen Ruhm verschaffte. Eigentlich hätte diese eine Expedition schon genügt, konnte man doch deren Ergebnisse mit jenen Meridianmessungen vergleichen, die in Frankreich selbst bereits angestellt worden waren. Doch richtete man, um ganz sicher zu gehen, eine zweite Expedition einer französischen Wissenschaftlergruppe zum Äquator aus, um einen zweiten Vergleichswert zu erhalten.

Wenn man in der französischen Akademie der Wissenschaften zum damaligen Zeitpunkt die Erdkugel drehte, um mögliche Zielregionen für diese zweite Expedition zu bestimmen, so zeigte sich rasch, dass sich als damals einzig zugängliche Region die Audiencia de Quito anbot, also jene Region, die im Bereich des heutigen Ecuador liegt. Die Leitung dieser im Vergleich mit Lappland wesentlich aufwendigeren Expedition wurde dem Mathematiker Louis Godin anvertraut, da es sich um letztlich mathematische Berechnungen handelte. Charles-Marie de La Condamine war zum damaligen Zeitpunkt nur ein einfacher Teilnehmer dieser französischen Expedition, doch sollte er aus verschiedenen Gründen recht bald der tatsächliche Leiter der an ihr beteiligten Académiciens und ein Rivale Godins werden.

Gestatten Sie einige wenige Worte zu Charles-Marie de La Condamine! Er war mit dem neuen Jahrhundert am 28. Januar des Jahres 1701 in Paris zur Welt gekommen, die er am 4. Februar 1774 ebendort wieder verließ. Als Sohn eines adeligen Steuerbeamten kam er an das renommierte Collège Louis-le-Grand 
und erfuhr eine ausgezeichnete Ausbildung. La Condamine schlug zunächst eine militärische Laufbahn ein und war mit einem Dragoner-Regiment 1719 am Krieg gegen Spanien und an der Belagerung von Roses beteiligt, bevor er seinen Lebensweg noch einmal änderte und sich den - im damaligen Sinne verstandenen - Naturwissenschaften und „Sciences physiques“ zuwandte. Dies sollte ihn zu hohen Ehren und unter anderem bereits ab 1730 zu einem Mitglied der Pariser Académie des Sciences sowie später der Académie française machen. Es ist nicht unwahrscheinlich, dass der mit ihm befreundete Voltaire bei der Aufnahme in die erstgenannte Akademie die Finger mit im Spiel hatte - und im Spiel hatten beide große Erfahrungen. Denn Voltaire und La Condamine soll es auf Grund der mathematischen Berechnungen des letzteren 1729-30 gelungen sein, die französische Lotterie zu knacken und zu zweit einen Reingewinn von immerhin einer runden Million Livres zu erzielen. Sie sehen: Das Studium der Wissenschaften kann manchmal für die eigene Laufbahn recht förderlich und ertragreich sein ...

Im Auftrag der Académie des Sciences sollte er bereits 1731 eine Reihe wissenschaftlicher Fragen des Mittelmeerraumes klären und insbesondere die nordafrikanische Küste erforschen. An Bord eines Freibeuterschiffes bereiste er die Mittelmeerküste bis zur Levante und trug später die Ergebnisse seiner Reise als Observations mathématiques et physiques faites dans un voyage de Levant vor. Doch seine größte Reise stand ihm noch bevor. In der britischfranzösischen Auseinandersetzung um die Gestalt unseres Planeten unterstützte La Condamines Freund Voltaire die These Newtons gegen Cassini; so gibt es gute Gründe dafür, mit der Forschung anzunehmen, dass Voltaire bei der Auswahl seines Freundes als Teilnehmer der Expedition in die Audiencia de Quito wiederum seine Finger mit im Spiel hatte. Auch später setzte sich La Condamine sehr geschickt für das wissenschaftlich Gebotene ein und plädierte in der zweiten Jahrhunderthälfte vehement für die Impfung gegen die Pocken, welche in der zweiten Phase beschleunigter Globalisierung bereits eine wichtige Rolle spielen sollten. Doch kehren wir zur Forschungsexpedition nach Südamerika zurück!

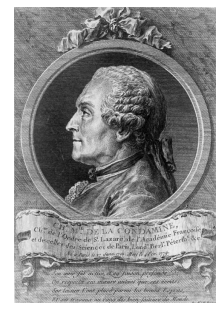

Abb. 22: Charles-Marie de la Condamine (1701-1774). 
Der spanische Hof gab sein Placet zu dieser Expedition relativ leicht, wenn man - wie bereits betont - aus verständlichen Gründen auch beschloss, die nie ungefährlichen Franzosen unter Bewachung zu stellen, oder sagen wir vornehmer: von spanischen Offizieren, die zum Teil ihrerseits wichtige wissenschaftliche Beobachtungen im Umfeld der Reise veröffentlichten, begleiten zu lassen. Vieles ist von dieser Expedition noch erhalten, nicht aber die französischen Orientierungsmarken der geometrischen und astronomischen Messungen, welche die Académiciens im spanischen Amerika durchführten, trugen sie doch die königlichen Lilien in provokativer Größe auf ihren Sockeln. Dies konnte auf spanischem Boden in den Kolonien nicht lange geduldet werden: Sie waren längst verschwunden, als ein gutes halbes Jahrhundert später Alexander von Humboldt auf seiner Expedition die Ergebnisse der französischen Messungen zu überprüfen versuchte.

Heutzutage führt man sehr viel präzisere Messungen durch, um die Frage nach der genauen Gestalt der Erde zu klären. Denn diese ist für die unterschiedlichsten Anwendungsgebiete vor allem im infrastrukturellen und militärischen Gebiet von großer Wichtigkeit. Dabei hat man es mittlerweile freilich leichter, kann man doch die Erde von außerhalb, vom Weltraum - sogar schon als gut zahlender Tourist - sehen, photographieren und selbstverständlich auch messen. Im 18. Jahrhundert verfügte man über eine Reihe terrestrischer Methoden, von denen die Triangulation besonders zuverlässig war, wobei man den zu messenden Bereich in Dreiecke einteilte, die man dann durch kleine Pyramiden für weitere Messungen kennzeichnete. Bereits 1670 hatte man in Frankreich mit Hilfe dieser Methode einen Meridians-Bogen ausgemessen, so dass man über genaue Vergleichsdaten zur Krümmung der Erdoberfläche verfügte. Die von Colbert gegründete Académie des Sciences beauftragte daraufhin verschiedene Wissenschaftler mit der Berechnung der Oberfläche ihres Heimatlandes; und diese Arbeiten wurden 1682 mit einer deutlichen Verbesserung der Karte Frankreichs abgeschlossen. Diese Experimente, Messungen und Erfahrungen wurden nun durch die Wissenschaftlergruppen der Expeditionen nach Lappland wie nach Südamerika auf die Messung des Äquatorialbogens übertragen. Im Grunde also ganz einfach!

So segelt denn ein französisches Kriegsschiff im Mai 1735 von La Rochelle aus los, an Bord zehn Wissenschaftler, die von der Académie für diese Untersuchung ausgewählt wurden. Unter ihnen, die allesamt durch den Monumentalbau unweit von Quitos Zentrum verewigt wurden, seien hier der Mathematiker und Astronom Louis Godin, der Astronom und Mathematiker Pierre Bouguer, der Naturalist und Arzt Joseph de Jussieu, ein Geograph, ein Uhrenspezialist was, wie wir gleich einsehen werden, besonders wichtig war -, ein Ingenieur, ein Techniker, ein Chirurg sowie eben unser Charles-Marie de La Condamine 
genannt. Diese französische wissenschaftlergruppe wurde im heute kolumbianischen Cartagena de Indias durch die kolonialspanischen Behörden ehrenvoll in Empfang genommen. Zwei Leutnants der spanischen Marine kümmerten sich um die französischen Gäste und deren Messungen, und zwar die später ausgezeichneten Jorge Juan y Santacilia sowie Antonio de Ulloa, die durch ihre Tätigkeiten und Kenntnisse hinsichtlich der Erforschung Amerikas ebenfalls zu Berühmtheiten wurden. Die beiden waren entgegen mancher französischen Darstellung keineswegs vorrangig mit Überwachungsaufgaben betraut: auch in Spanien und seinen amerikanischen Kolonien hatte längst die Aufklärung mit ihren wissenschaftlichen Methoden Einzug gehalten.

Die ab diesem Zeitpunkt in Begleitung kolonialspanischer Vertreter durchgeführte Reise führte unsere Akademiker von Cartagena de Indias nach Portobelo, dann weiter durch den mittelamerikanischen Isthmus über den Río Chagres und zu Fuß nach Panamá am Pazifischen Ozean, von dort dann nach Manta und schließlich Guayaquil im heutigen Ecuador. La Condamine und sein späterer Gegenspieler Bouguer verließen die Expedition bereits in Manta und begannen mit ihren Messarbeiten schon auf dem Weg hoch nach Quito. Dies ist eine Route, von der wir quer durch die Jahrhunderte immer genauere Messungen haben. Durch die astronomische Beobachtung der glücklich eingetretenen Mondfinsternis von 1736 gelang es ihnen, die genauen Koordinaten der Küste und des Küstenverlaufs zu bestimmen, welche in diesem Bereich den westlichsten Vorsprung der Küste Südamerikas bildet. Das Ergebnis all dieser mühseligen Messungen war eine Berichtigung der Karten hinsichtlich des genauen Küstenverlaufs in diesen Breiten, ein mit Blick auf die Sicherheit der Schifffahrt keineswegs nebensächlich zu nennendes Resultat.

Doch die Spannungen innerhalb der binationalen Gruppe steigen: Gegenseitige Rivalitäten und Verdächtigungen verschaffen sich zunehmend gehör. Die unterschiedlichen Messungen und Forschungen der Franzosen werden recht argwöhnisch auch vor Ort von den spanischen Kolonialbehörden beäugt. Die französische Reiseliteraturforscherin Hélène Minguet verweist sogar darauf - und ich lege nicht die Hand dafür ins Feuer, dass dies nicht noch Auswirkungen der französischen Sichtweise des ungebildeten und habgierigen Spanien sind -, man habe den Verdacht geschöpft, die Franzosen könnten den Plan gefasst haben, sich des berühmten, aber niemals gefundenen Inkaschatzes zu bemächtigen. ${ }^{4}$ Als die Franzosen 1739 in Cuenca und damit im andinen

4 Vgl. hierzu Minguet, Hélène: Introduction. In: La Condamine, Charles-Marie de: Voyage sur l'Amazone. Choix de textes, introduction et notes de Hélène Minguet. Paris: François Maspéro, 1981, S. 5-27. 
Hochland ankommen, erfahren sie, dass Maupertuis und dessen Expedition mittlerweile aus Lappland zurückgekehrt sind und die These Newtons bestätigt wurde: Die Erde - dies weiß man also seit 1739 - ist an den Polen abgeplattet und am Äquator ausgebuchtet. Damit stand auch fest, dass die französische Südamerika-Expedition nicht mehr als erste den Nachweis für diese These Isaac Newtons würde erbringen können.

Die Enttäuschung der französischen Wissenschaftler muss riesig gewesen sein. Denn sie waren nun bestenfalls noch in der Lage, die Ergebnisse ihrer Landsleute in Lappland zu bestätigen. Wissenschaftsgeschichte aber konnten sie, das wussten nun alle, nicht mehr schreiben - zumindest schien es so. Doch in diesem Punkte ging La Condamine eigene Wege und ließ später aus einer persönlichen Perspektive diese Reise doch noch zu einem Triumphzug für sich werden, wenn die eigentliche Aufgabe der Académie des Sciences auch längst erfüllt war.

Allerdings war das weitere Geschick der gesamten Expedition als überaus problembehaftet zu bezeichnen, denn es stellten sich allerlei Schwierigkeiten und Auseinandersetzungen zwischen den Mitgliedern der Expedition untereinander, aber auch mit der Bevölkerung ein, die unter anderem sogar zur Ermordung eines der Expeditionsmitglieder führten. Die Atmosphäre um die Franzosen verdüsterte sich. Man verdächtigte sie etwa, französische Spione zu sein, Liebeshändel kamen hinzu und La Condamine sowie seine Begleiter wurden vor Gericht gestellt. 1743 schließlich brach der sich langsam aufschaukelnde Streit zwischen Bouguer und La Condamine offen aus: Ersterer brach alle laufenden Arbeiten ab und reiste nach Cartagena, um sich von dort aus zurück nach Frankreich einzuschiffen und als erster vor der Académie des Sciences von den Ergebnissen der Expedition zu berichten. La Condamine fühlte sich daher frei, dem Vorschlag des Forschers Maldonado zu folgen und den Amazonas hinunterzufahren, um von dessen Mündung aus dann den Rückweg nach Frankreich anzutreten. Damit nahm er sich vor, eine der bis zum damaligen Zeitpunkt immer noch unbekanntesten Binnenregionen des Subkontinents zu erforschen. Es hätte sicherlich leichtere und sicherere Wege gegeben, die La Condamine nach Frankreich zurückgebracht hätten.

Die gewählte Reiseroute führte den französischen Naturforscher und Wissenschaftler zunächst nach Loja in den Hochanden, das auch unter der Schreibweise Loxa zum damaligen Zeitpunkt für seine Fieberrinde berühmt war - auch Alexander von Humboldt sollte sich diese Kulturen auf seiner Reise durch die Anden näher ansehen und untersuchen. Der Weg führte dann, möglicherweise über das schöne Huancabamba, hinunter nach Borja und damit zum Übergang in das Tiefland am Amazonas. Wir werden uns diese Passage des Reiseberichts gleich noch aus der Nähe anschauen. Es folgte eine faszinierende Flussfahrt mit der Untersuchung von Flora und Fauna des Amazonas-Tieflands, wobei vieles 
bis zu diesem Zeitpunkt in Europa völlig unbekannt war. Die Wahrnehmung des Franzosen blieb freilich ganz auf den Flusslauf des Hauptstromes begrenzt, da keine Zeit für Expeditionen blieb, welche diesen ,Tunnelblick ${ }^{6}$ hätten erweitern können. La Condamine bemühte sich, Neueres über die Flussverbindung zwischen Amazonas und Orinoco über den Río Negro und den Casiquiare herauszufinden. Jedoch zweifelte er an dieser tatsächlich existierenden Verbindung, die später durch Alexander von Humboldt nachgewiesen wurde, ebenso wenig wie an der Existenz der Amazonen, jener mythischen Frauen, gegen welche die spanischen Konquistadoren des 16. Jahrhunderts gekämpft zu haben vorgaben und die dem Fluss in der Nachfolge dieses unter anderem von Orellana transponierten Mythos auch den Namen gaben. Die Kartenwerke des 18. Jahrhunderts wiesen gerade im Binnenland Amerikas große weiße Flecken und sagenumwobene Gebiete auf; La Condamine stand im Begriff, für eine der wichtigsten dieser Regionen nähere Informationen zu liefern.

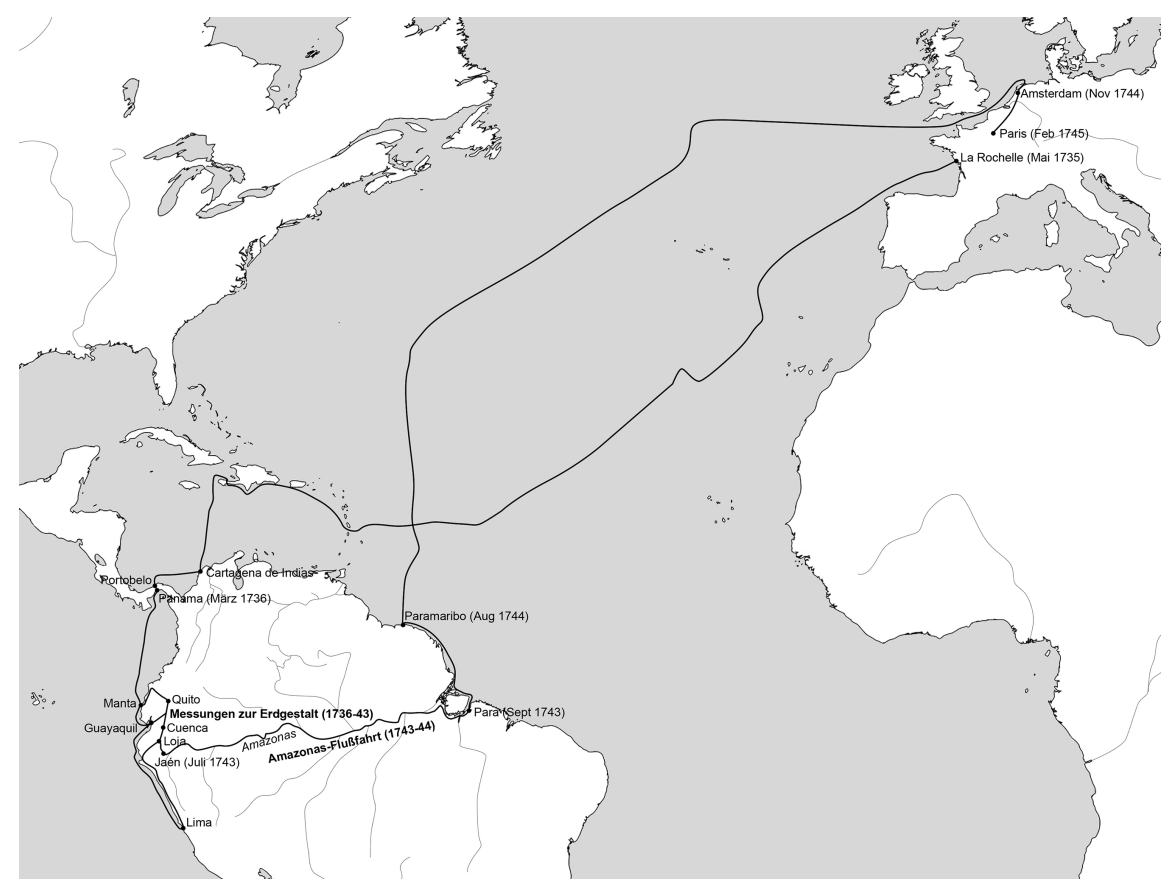

Abb. 23: La Condamines Reiseroute.

Doch der Franzose stand nach seiner Rückkehr in Frankreich vor einem doppelten Problem. Zum einen war die Frage der Abplattung der Pole und der Ausbuchtung des Äquators längst und definitiv geklärt, so dass Messungen und 
Angaben hierzu als völlig redundant angesehen werden mussten. Zum anderen war sein Rivale Bouguer lange vor ihm zurückgekehrt und hatte ausführlich in mehreren Vorträgen vor der Académie des Sciences über die Ergebnisse der Expedition berichtet, so dass La Condamine auch in diesem Bereich kaum wissenschaftliche Lorbeeren würde ernten können. Denn auch dieses Kapitel war mit Bouguers Vorträgen seit November 1744 abgeschlossen, hatte La Condamines Gegenspieler doch ausführlich von den Resultaten in den Hochanden berichtet. La Condamine konnte seinerseits erst im April 1745 wieder vor der französischen Akademie der Wissenschaften auftreten. Bereits bei diesem ersten Auftreten trug er einen gekürzten Bericht von seiner Flussfahrt den Amazonas hinunter vor. Das wissenschaftliche Interesse verlagerte sich nun ganz auf diese Episode seiner insgesamt zehnjährigen Reise, waren die französischen Wissenschaftler doch im Mai 1735 nach Südamerika aufgebrochen.

Charles-Marie de La Condamine verknüpfte fortan geschickt seinen Namen mit der eher kurzen Zeit im Amazonas-Gebiet. Zu diesem Bereich des Inneren Südamerikas gab es vor ihm nur spärliche Berichte. Der Franzose verstand es, die Aufmerksamkeit seiner Zuhörer und später seiner Leserinnen und Leser gerade dadurch zu gewinnen, dass er in recht kunstvollen Perioden nicht nur einen Bericht seiner Reise bot, sondern zugleich auch auf eine Vielzahl einschlägiger Mythen und Legenden einging. Diese reichten von den kriegerischen Amazonen über die in Frage stehende Flussgabelung, und vor allem von der französischen „Géographie systématique“ bezweifelte Bifurkation des Casiquiare bis hin zur Legende um El Dorado vom Parime-See, dem vergoldeten König, der noch immer die europäischen Träume von einem versteckten Schatz mit viel amerikanischem Gold befeuerte. La Condamine versuchte zudem, die bisherige Entdeckungs- und Eroberungsgeschichte des Oberen Marañón und des Amazonas darzustellen: von den Fahrten Orellanas bis zum Pater Fritz. In besonderem Maße bezog er sich aber auf jene legendenträchtige Reise des Lope de Aguirre den Amazonas hinunter, die nicht nur zu einer Vielzahl literarischer Darstellungen und Romane führte, sondern darüber hinaus den Ausgangspunkt für die Ihnen sicherlich bekannte monumentale Filmfassung Werner Herzogs mit dem Titel Aguirre oder der Zorn Gottes bot. ${ }^{5}$ Sie sehen, wir befinden uns in einem mythenreichen und bis heute mythenreich gebliebenen Landstrich!

5 Vgl. hierzu die nicht weniger monumentale Habilitationsschrift von Galster, Ingrid: Aguirre oder Die Willkür der Nachwelt. Die Rebellion des baskischen Konquistadors Lope de Aguirre in Historiographie und Geschichtsfiktion (1561-1992). Frankfurt am Main: Vervuert 1996. 
Widmen wir uns also jenem Abschnitt der Reise, für den Charles-Marie de La Condamine berühmt wurde: der Amazonasfahrt. Im Mai 1743 trat La Condamine seine Reise von Tarqui aus an, wobei er zunächst einen Umweg wählen muss, da die Mörder seines ehemaligen Mitreisenden ihm einen Hinterhalt legten, um jegliche Prozessakten und Aktennotizen auf dem einfachsten Wege zu vernichten und ihn ins Jenseits zu befördern. Am 4. Juli 1743 begann dann die eigentliche Flussfahrt La Condamines: Am nächsten Tag schon ist der Marañón, der obere Amazonas also, erreicht. Schließlich gelangt man zum Pongo de Manseriche, wobei der Begriff „Pongo“ gleich „Tor“ hier sowohl landschaftlich als auch reiseliterarisch überaus zutreffend erscheint. Denn der französische Literat - der Wissenschaftler hegte durchaus literarische Ambitionen und gelangte nicht von ungefähr später in die Académie française - verwandelte diese Passage in einen literarischen Höhepunkt seines ausgefeilten Reiseberichts. Der Pongo de Manseriche wurde gleichsam zum Eingangstor in den Zentralbereich seines Berichts von der Flussfahrt über den Amazonas. Und plötzlich befinden wir uns im Zentrum jener Welt, die La Condamine nun meisterhaft darzustellen beginnt:

In Borja angekommen, fand ich mich in einer neuen Welt wieder, weitab von jedem menschlichen Verkehr, auf einem Meer von Süßwasser, inmitten eines Labyrinths aus Seen, Flüssen und Kanälen, die in allen Himmelsrichtungen einen ungeheuren Urwald durchziehen, den sie allein zugänglich machen. Ich stieß auf neue Pflanzen, neue Tiere, neue Menschen. Meine Augen, seit sieben Jahren daran gewöhnt, die Berge sich in den Wolken verlieren zu sehen, konnten nicht davon ablassen, ständig den Horizont zu umgreifen, ohne dass sich ihnen ein anderes Hindernis in den Weg gestellt hätte als die Hügel des Pongo, die aus meinem Gesichtskreis bald verschwinden sollten. Dieser Menge an unterschiedlichen Gegenständen, welche die bebauten Ländereien in der Umgebung von Quito bereichern, folgte nun der gleichförmigste Anblick: Wasser, Grün, und nichts weiter. Man durchfurcht die Erde mit seinen Füßen, ohne sie zu sehen; sie ist so von dichten Gräsern, von Pflanzen und Gebüschen bedeckt, dass es einer recht langen Arbeit bedürfte, um die Fläche eines einzigen Fußes freizulegen. Unterhalb von Borja und vier- bis fünfhundert Meilen den Fluss hinunter ist ein Fels, ein einfaches Steinchen, etwas ebenso Seltenes wie ein Diamant. Die Wilden dieser Gegenden wissen nicht, was ein Stein ist, ja haben davon nicht einmal eine Vorstellung. Es ist ein vergnügliches Schauspiel, einige von ihnen nach Borja kommen zu sehen und zu beobachten, wie sie zum ersten Male darauf stoßen und ihre Bewunderung durch ihre Zeichen kundtun, sich beeilen, sie zusammenzuraffen, sich damit wie mit einer wertvollen Handelsware zu beladen und doch bald darauf voller Verachtung wegzuwerfen, sobald sie bemerken, dass diese Steinchen so verbreitet sind. ${ }^{6}$

6 La Condamine, Charles-Marie de: Voyage sur l'Amazone, S. $60 \mathrm{f}$. 
Da ich einen Teil dieser Passage bereits ausführlich im theoretischen Teil meiner Vorlesungen zur Reiseliteratur interpretiert habe, ${ }^{7}$ will ich an dieser Stelle einige Aspekte von La Condamines ,Eingangstor' in seinen Reisebericht betonen und weitere Überlegungen zu der hier entfalteten Landschaft der Theorie ${ }^{8}$ anschließen. Denn der Pongo markiert den Übergang von einer Welt des Dreidimensionalen zu einer Welt des Zweidimensionalen, wo sich Wasser und Grün ständig neu kombinieren. Sie tun dies nicht zuletzt in Form labyrinthischer Verschlingungen, die sich aus der Perspektive der Zweidimensionalität kaum entwirren lassen, sondern die eine Aufzeichnung als Karte notwendig machen, so dass ein Blick von oben entstehen kann, der Klarheit schafft. In dieser Welt miteinander verbundener Gewässer ist alles mit allem verbunden, wobei die Wege nun zu Wasserwegen geworden sind: Das Land zwischen den Wassern ist nicht für Wege gemacht.

Der Europäer betritt diese neue, von der andinen abgetrennte Welt mit dem Blick eines Entdeckers, der die geheimen Verbindungen aufdecken und die gesamte Anlage verstehen will. Geradezu euphorisch tritt Klarheit in diese Landschaft, die sich dem Blick erschließt. Fast will es scheinen, dass die Last der Dreidimensionalität, die noch im andinen Raum schwer auf dem Reisenden lastete, nun von ihm abfällt und einer wachsenden Begeisterung Platz macht, da diese Neue Welt nun seinem Verstehen und Begehren offensteht.

Voraussetzung für die erstrebte Klarheit und Transparenz ist aber die Erstellung eines Plans, einer Karte, welche diesen Strom, seine Flüsse und Nebenflüsse zu erfassen vermag. Auch wenn der reale La Condamine all diese Informationen mit den ihn begleitenden spanischen Gelehrten, den indianischen Ruderern sowie weiteren Begleitern, die im Reisebericht des Franzosen freilich weitestgehend ausgespart werden, teilt, entsteht eine Fokussierung auf ein sich wandelndes, dieser Landschaft der Theorie anpassendes Subjekt. Dieses hat bereits den Weg zu einer modernen Subjektwerdung eingeschlagen und beginnt im Verhältnis zur amerikanischen Natur, ja in der Konfrontation mit der amerikanischen Natur, sich selbst viel klarer zu reflektieren. Dieses Ich erlebt sich selbst als die gesamte sich darbietende Natur umfassende europäische Forscherpersönlichkeit. Eine Landschaft der Theorie als Landschaft der Zweidimensionalität erlaubt es dem Forscher, sich selbst gegenüber den Objekten der Natur wie auch den Menschen, die dort leben, in eine kritische, unverkennbar wissenschaftliche Distanz zu setzen.

7 Vgl. Ette, Ottmar: ReiseSchreiben. Potsdamer Vorlesungen zur Reiseliteratur. Berlin - Boston: Walter de Gruyter 2020, S. 161-163.

8 Vgl. hierzu Ette, Ottmar: Roland Barthes. Landschaften der Theorie. Konstanz: Konstanz University Press 2013. 


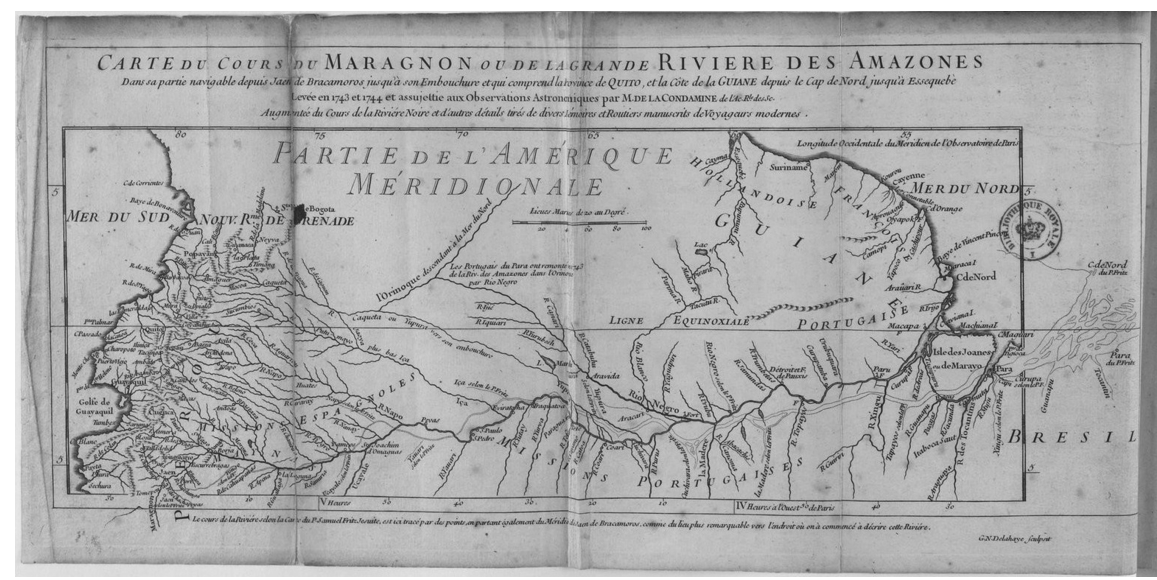

Abb. 24: Amazonas-Karte in La Condamines Relation abrégée d'un voyage fait dans l'intérieur de l'Amérique méridionale.

Die mythischen Gegenstände, die den Forscher erwarten, verwandeln diesen Europäer in eine historische Größe, die alles - die amerikanische Flora wie die Fauna, die Menschen wie ihre Mythen, die Gewässer und die Wasserwege beherrscht. Er erblickt die Kleinheit der Menschen, vermag ihr Erstaunen zu verstehen, ihre Begrenzungen zu erkennen, ihre Lage zu beschreiben. Nichts ist vor seinem analytischen, alles durchdringenden Blicke geschützt. Das reisende Ich weiß sich in der Kontinuität dieser abendländischen Mythen, die von der Alten in die Neue Welt transportiert und anverwandelt wurden: Die Amazonen sind Teil jener Bildungsausstattung, welche die Welt der griechischen Antike, die mythische Welt des Mittelmeeres, in diese Welt einer Flusslandschaft mit ihren Flussinseln und Verzweigungen projiziert. Die Neue Welt des Amazonas ist dem Reisenden damit zugleich eine vertraute Welt, die auch für das Lesepublikum nach einer ersten Überraschung bald als fremd und vertraut zugleich erscheinen wird. Im prüfenden, strukturierenden Blick des reisenden Ich ordnet sich ein zunächst undurchdringliches Chaos des Verschlungen-Seins zu einem Kosmos an, zu einer Welt, die in Ordnung und Schönheit den rational alles durchdringenden Verstand des Ich umfängt. Trotz aller Gefahren, die den Reisenden im Labyrinth erwarten, trotz aller Bedrohungen, für welche die noch unbekannten Amazonen im Verbund mit den „Sauvages“, den „Wilden“, stehen mögen, ist der reisende Europäer sich doch seiner selbst sicher. Nicht mit Angst, sondern mit großen Erwartungen betritt der europäische Forscher die für ihn neue, labyrinthische Welt: Er wird aus diesem Labyrinth mit Hilfe seines Fadens der Ariadne gewiss wieder herausfinden. 
Mit Charles-Marie de La Condamines Voyage sur l'Amazone lesen wir einen Text, der weit über das Dokumentarische eines Reiseberichts hinausgeht und als literarischer Text eines Schriftstellers anerkannt und gelesen werden will. Es geht nicht nur um eine ,Beschreibung' der Reise auf dem Amazonas, sondern um erzählende Prosa, in deren Mittelpunkt die Vielzahl von Verweisen auf andere literarische Texte, Mythen und Legenden steht. Dabei bedient sich La Condamine eines literarischen Stils, der den Aufbau eines komplexen innerliterarischen Raumes begünstigt, möchte er doch weniger, dass seine Leserschaft eine möglichst genaue Vorstellung von den materiellen Grundlagen und Bedingungen seiner Flussfahrt erhält, sondern vielmehr die Möglichkeit erhält, diese Reise in komplexe literarische Muster vergleichbarer Erkundungsreisen zu stellen. Und diese unzweideutig als literarisch zu bezeichnenden Zielsetzung erreicht der französische Schriftsteller mit Bravour. Die simple Augenzeugenschaft tritt angesichts der selbstgestellten Aufgabe merklich in den Hintergrund.

Dies entspricht sehr wohl den architextuellen Vorgaben für den Reisebericht im 18. Jahrhundert. Denn diese Gattung oszilliert oder pendelt zwischen Diktion, also der möglichst ästhetischen Darstellung real durchquerter Landschaften und Gebiete, und der Fiktion: Reiseliteratur ist Friktion, ${ }^{9}$ mithin die gezielte Bewegung zwischen nicht-fiktionalen und fiktionalen Bestandteilen des Erzählens. Die auf die außersprachliche Wirklichkeit verweisenden, von späteren Reisenden auch überprüften Landschaftselemente wie etwa der Pongo de Manseriche werden im Verbund mit spezifisch literarischen Techniken von Inszenierung und intertextuell potenzierter Semantisierung in eine unabschließbare oszillierende Bewegung gebracht, die nicht auf das Dokumentarische reduziert werden kann, sondern den friktionalen Status dieser Querung einer aquatischen Landschaft unterstreicht. Das Labyrinth ist tausendfach präsent.

Die narrative Grundstruktur der Voyage sur l'Amazone ist daher aufschlussreich: Führen wir uns die Komplexität der Ich-Figur in diesem Reisebericht vor Augen! Das Ich ist in dieser Passage zugleich auf einer referentialisierbaren Ebene der Reisende und Naturforscher, der den oberen Marañón durchquert. Auf einer historisch-literarischen Ebene ist es der Erbe des Christoph Kolumbus, der einst vor der Mündung des Orinoco von einem Süßwassermeer gesprochen hatte. Auf einer Ebene der griechischen Mythologie wird es zum Nachfolger des Theseus, diesen überbietend, indem es mit Hilfe seiner von ihm selbst gezeichneten Flusskarte den Faden finden wird, der ihn aus dem Labyrinth siegreich wieder herausführen kann. Auf einer psychoanalytischen Ebene feiert jenes Ich

9 Vgl. hierzu Ette, Ottmar: ReiseSchreiben. Potsdamer Vorlesungen zur Reiseliteratur, S. 141-149. 
die Immersion im Wasser wie eine Ekstase und die aquatische Landschaft der „mer d'eau douce“ wie eine pränatale Wiedervereinigung mit der Mutter ekstatisch. La Condamines literarischer Reisebericht öffnet sich unterschiedlichsten Lesarten.

So wird die angeführte Passage in mehrfacher Hinsicht kodiert und als Höhepunkt (sowie als Überschreitung einer Grenze) inszeniert. Der in der realen Landschaft vorhandene Pongo de Manseriche fungiert auf Ebene des literarischen Textes wie die Eröffnung des Betretens einer neuen, aquatischen Welt, in welcher die Dreidimensionalität zurücktritt, um der Verschlungenheit des Zweidimensionalen den Raum zu überlassen. Eine Einebnung des Textes auf die erste, referentialisierbare Ebene würde dem friktionalen Textstatus bei weitem nicht gerecht: Wir würden die polysemen, vieldeutigen Inhalte des Voyage sur l'Amazone nicht erfassen. Denn die Polysemie des verdichteten semantischen Materials eröffnet viele parallele Lesarten und Lese-Modi, die sich nicht auf eine dokumentarische Eindimensionalität zurückführen lassen, sondern eine Lust am Text entfalten, die sich aus dessen Viellogik und Vieldeutbarkeit speist. Dass La Condamines Reisebericht in Frankreich Furore machte und sowohl auf seiner beschreibenden wie auf seiner literarischen Ebene eine herausragende Stellung innerhalb der damaligen französischen Reiseliteratur beanspruchte, versteht sich von selbst. Der Autor war nicht nur mit guten Gründen in die Académie des Sciences aufgenommen worden, er wurde auch zu Recht in die Académie française gewählt.

Man kann durchaus die Behauptung wagen, dass mit La Condamines Reisebericht eine neue Etappe innerhalb der reiseliterarischen Gattung beginnt, zugleich aber auch eine neue Phase in der Auseinandersetzung Europas mit dem amerikanischen Kontinent und insbesondere dessen Naturphänomenen. Amerika - und vor allem das tropische Amerika - war nun deutlich in den Fokus abendländischer Erkundung und okzidentalen Wissens gerückt. $\mathrm{Zu}$ gleich wurden auch im ästhetischen Bereich neue Sichtweisen des amerikanischen Kontinents erprobt, welche die Landschaftsdarstellungen von Amerika vor allem in der zweiten Hälfte des 18. Jahrhunderts zu verändern begannen. In diesem Zeitraum wurden nicht mehr nur europäische Bergwelten ästhetisiert, wie wir dies in Jean-Jacques Rousseaus Briefroman Julie ou la Nouvelle Héloïse beobachten können, sondern auch außereuropäische Gebirgswelten, wofür Bernardin de Saint-Pierres kleiner, aber einflussreicher Roman Paul et Virginie stehen mag. Mit Alexander von Humboldt springt die Ästhetisierung der dritten Dimension auf eine neue Sichtweise der Gebirge und Vulkane in den Hochanden über und erzeugt eine grundlegend veränderte, auch literarisch innovative Sichtweise amerikanischer Landschaften. Dass eine solche veränderte Sichtweise auch eine andere Landschaft der Theorie und damit Epistemologie 
beinhaltet, ist angesichts der wissenschaftlichen Relevanz des letztgenannten Beispiels offenkundig. Dieser neue Blick war der im 18. Jahrhundert sich herausbildende und gegen Ende des Jahrhunderts konkretisierende Blick der Moderne auf die amerikanischen Landschaftsformationen.

Doch Charles-Marie de La Condamine beschränkte sich keineswegs auf die Beschreibung und literarische Darstellung von Naturphänomenen, also auf das, was wir klassisch als ,Landschaft' zu bezeichnen pflegen. Unmittelbar im Anschluss an die zitierte Eingangspassage, an deren Ende ja bereits ein Ausblick auf die Bewohner des Tieflandes rund um den Oberen Marañón oder Amazonas erfolgt, schließt sich eine zweite, für die anthropologische oder ethnologische Dimension sehr wichtige Passage an, welche die Frage der Ureinwohner, der indigenen Bevölkerung also, berührt. La Condamine versuchte, dem französischen beziehungsweise europäischen Lesepublikum einen allgemeinen Eindruck von diesen „Wilden“ („sauvages“) im Allgemeinen und von den Bewohnern des Oberen Marañón im Besonderen zu vermitteln. Wir müssen uns an dieser Stelle auf die zentralen Elemente dieser Passage beschränken:

Bevor ich mich mit anderem beschäftige, glaube ich ein Wort über Geist und Charakter der ursprünglichen Bewohner des südlichen Amerika sagen zu müssen, welche man gemeinhin, wenn auch fälschlich, als Indianer bezeichnet. An dieser Stelle geht es nicht um die Frage der spanischen oder portugiesischen Kreolen und auch nicht um die verschiedenen Arten von Menschen, die ein Produkt der Vermischung der Weißen aus Europa mit den Schwarzen aus Afrika und den Roten aus Amerika sind, seitdem die Europäer hier auftraten und Neger aus Guinea eingeführt haben.

$[\ldots]$

Um eine genaue Vorstellung von den Amerikanern zu geben, bräuchte es fast ebenso viele Beschreibungen, wie es Nationen unter ihnen gibt; doch sind sie wie alle Nationen Europas zwar untereinander verschieden in ihren Sprachen, Sitten und Gebräuchen, entbehren aber keineswegs gemeinsamer Züge in den Augen eines Asiaten, der sie aufmerksam betrachtete, und so schienen mir alle amerikanischen Indianer der unterschiedlichen Gebiete, die ich im Verlauf meiner Reise zu sehen Gelegenheit fand, gewisse Züge der Ähnlichkeit miteinander zu teilen; und (von einigen Nuancen abgesehen, die zu erfassen es einem Reisenden, der die Dinge nur im Vorübergehen sieht, kaum erlaubt sind) so habe ich geglaubt, bei ihnen allen denselben charakterlichen Grundzug zu erkennen.

Für alles bildet ihre Unempfindlichkeit die Grundlage. Ich lasse zur Entscheidung offen, ob man sie mit dem Namen Apathie beehren oder mit dem der Stumpfheit in den Schmutz ziehen möchte. Sie entsteht zweifellos aus der kleinen Anzahl ihrer Ideen, die sich nicht über den Bereich ihrer Bedürfnisse hinaus erstrecken. Bis zur Gefräßigkeit verschlingend, wenn sie über alles zu deren Befriedigung verfügen; sparsam, sobald die Notwendigkeit sie dazu treibt, sogar bereit, auf alles zu verzichten, ohne überhaupt etwas zu begehren; im Übermaße furchtsam und feige, wenn die Trunkenheit sie nicht beflügelt; der Arbeit gegenüber feindselig, unempfindlich für jeden Anreiz des Ruhmes, der Ehre oder der Dankbarkeit; einzig mit dem gegenwärtigen Gegenstand beschäftigt und stets 
von ihm eingenommen; ohne jede Sorge um die Zukunft; unfähig zur Voraussicht und zum Nachdenken; sich einer kindlichen Freude überlassend, die sie durch Sprünge und unbändiges Lachen grund- und planlos kundtun, wenn nichts sie stört; sie verbringen ihr Leben, ohne zu denken und werden älter, ohne ihre Kindheit, von der sie alle Fehler bewahren, zu verlassen. ${ }^{10}$

Diese Passage aus La Condamines Voyage sur l'Amazone macht deutlich, wie sehr die Betonung einer kritischen Distanz, welche der Betrachter zu Beginn der Ausführungen einnimmt, einer Position Platz macht, die umso unverblümter ihre pauschalen Beurteilungen und Verurteilungen im Gewande überlegter Kritik kundtut. Kritik - und sie steht ja im Zentrum der Aufklärung - ist also nicht gleich Kritik! Denn die eigene europäische Position wird nicht wirklich selbstkritisch reflektiert, sondern dünkt sich erhaben über die beschriebenen Gegenstände und all jenen Kulturen überlegen, welche hier in wenigen generellen Werturteilen eindeutig verurteilt werden. Auch die Geste, den Leserinnen und Lesern die Entscheidung darüber zu lassen, wie die Indianer letztlich zu beurteilen seien, erweist sich nach Lektüre der gesamten Passage als rein rhetorische Floskel.

Die Passage macht überdies deutlich, wie sehr die Einschätzung der Indianer - sehr zurückhaltend formuliert - bestimmten Gesetzlichkeiten interkultureller Wahrnehmung gehorcht. La Condamine ist durchaus nicht jener unbeteiligte Asiate, der die indigene Bevölkerung aufmerksam (und vorurteilsfrei) beobachtet. Er ist vielmehr Partei: Er ist ein Forscher, der als Europäer auf der Seite des europäischen Kolonialismus steht. Denn das hier entfaltete Bild der indigenen Bevölkerung entspricht genauestens jenen Vorurteilen, die man in Europa mit den ,Indianern“ im 18. Jahrhundert zu verbinden pflegte und bestätigt alle Heterostereotypen, die sich gerade auch in den nachfolgenden Debatten im Europa der Aufklärung über die Amerikaner verfestigen sollten. Die Indianer, so lernen wir, sind dumm und arbeitsscheu. Und doch sind sie es, die etwa als Ruderer den französischen Wissenschaftler durch das Labyrinth sich verzweigender Flussläufe nicht nur geleiten, sondern führen.

Gehen wir die Argumente La Condamines einzeln durch! Da ist zum einen die Frage der Heterogenität, der Mannigfaltigkeit, die in irgendeiner Weise behandelt und überwunden werden muss, um ein einheitliches Gesamtbild - in diesem Falle der indigenen Bevölkerung - zu liefern. Denn jede indigene „Nation" unterscheidet sich von den anderen durch ihre Sprache, ihre Sitten und Gebräuche, ja selbst durch ihr Aussehen und wohl auch ihr Verhalten. Gewiss

10 La Condamine, Charles-Marie de: Voyage sur l'Amazone, S. $61 \mathrm{ff}$. 
ist hierbei die extreme Sprachenvielfalt, die Vielzahl an höchst unterschiedlichen Sprachen, aber auch Ethnien und Völkerschaften, ein nicht hinweg zu leugnendes Faktum, welches ein Reisender - oder eher ,Durchreisender “ nicht adäquat zu erfassen vermag. La Condamine macht mit dieser Diversität indigener Lebensformen kurzen Prozess. Er stellt die kulturelle Heterogenität und Diversität kurz fest, um dann umso besser und allgemeiner alle Völkerschaften über denselben Leisten, einen europäischen Leisten, zu schlagen. Noch sind wir weit von einer tatsächlichen Auseinandersetzung mit anderen Kulturen und deren Vielgestaltigkeit entfernt.

Dennoch betont der französische Wissenschaftler die von ihm durchaus beobachtete Heterogenität. Deren Darstellung gelingt ihm mit Hilfe eines kleinen Kunstgriffs, indem er vor Augen führt, wie unterschiedlich die einzelnen europäischen Nationen sind, wie gleichförmig sie aber doch einem außenstehenden Beobachter - wie etwa einem Asiaten - erscheinen müssten, wenn dieser auch sie, also die Europäer insgesamt, in den Mittelpunkt seiner Überlegungen rückte. Von daher wird eine Art genereller Grundlage konstruiert, wobei deutlich wird, dass hier auch nicht die Franzosen den Amerikanern entgegengestellt werden, sondern die Europäer insgesamt. So bildet sich durch eine imaginär angenommene und pro forma eingenommene Außenperspektive ganz rasch die Einheit des vermeintlich Eigenen heraus. Und zugleich auch die Einheit des vermeintlich ,Anderen', das nun als absolute Alterität zum ,absolut Anderen' stilisiert werden kann.

Doch La Condamines Argumentation versichert sich noch einer weiteren Vorkehrung. Denn zum Zweiten wird eine Art Kautele eingeführt, insoweit der Reisende seinen eigenen Beobachterstandpunkt relativiert, sei dieser doch lediglich der Blickwinkel des rasch Vorüberziehenden, des vorbeifahrenden Reisenden, der die Dinge nur en passant sehen und wahrnehmen könne. Dies ist bei einem so langjährigen Aufenthalt von La Condamine im Reich der Indianer eine etwas überraschende Wendung, auch wenn man sicherlich eingestehen muss, dass die eigentliche Flussfahrt auf dem Amazonas und die sich daraus ergebenden Möglichkeiten, die Tieflandindianer am Amazonas zu beobachten und mit ihnen in Kontakt zu kommen, höchst gering und bestenfalls sporadisch waren. Doch die Relativierung ist reine Rhetorik, denn diese Kautele erlaubte es dem Franzosen, ein generelles Bild der Indianer zu zeichnen, ohne sich um Details wie die Überprüfung der eigenen Aussagen kümmern zu müssen. Wie aber sah dieses Bild der höchst unterschiedlichen Völker am Amazonas nun aus? Wie beurteilte er jene indigene Bevölkerung, die ihn in Gestalt von Ruderern und Führern auf dem Fluss begleitete?

Die ,kritische‘ Wahrnehmung der ,Indianer' durch La Condamine geht von einem Negativum aus: ihrer „,insensibilité“, ihrer Gefühllosigkeit und Dumpf- 
heit, welche alle ihre Lebensbereiche erfasse. Damit wird ein Fehlen zur Grundlage gemacht, ein Nicht-Vorhandensein, welches stets den Hinweis auf ein Vorhandensein, auf ein andernorts, in Europa, Gegebenes miteinschließt, das wiederum positiv bewertet wird. Gewiss, wir haben es noch nicht mit jener „sensibilité“, mit jener „Empfindsamkeit“ zu tun, welche in einer Phase des Übergangs das Aufklärungszeitalter hin auf die Romantik öffnete. In der Tat sind die meisten Charakteristika, die in der Folge mit Blick auf die indigene Bevölkerung aufgezählt werden, Negativa, die für einen Mangel, für ein Fehlen stehen, das nur einen behaupteten Mangel gegenüber Europa darstellt. Man geht folglich von etwas in Europa (ganz selbstverständlich) Gegebenem aus, um dessen Fehlen in den Amerikas zu konstatieren. So erscheinen die Europäer im Umkehrschluss als sensibel und empfindsam, zugleich aber auch an der Arbeit sowie an Ruhm, allerlei Ehren und Verdienst(möglichkeit)en ausgerichtet. La Condamine zeichnet im Grunde zwei Stereotype: ein Heterostereotyp, das zugleich und aus umgekehrter Perspektive betrachtet aber auch ein Autostereotyp bilden kann.

Umgekehrt werden in diesem Zusammenhang positive Werte aus den Amerikas ausgeschieden, die auf einen Mangel in Europa hinweisen könnten, rücken also überhaupt nicht ins Blickfeld, ja wohl nicht einmal ins Bewusstsein des scheinbar so objektiven europäischen Betrachters. Denn was ließe sich über die Vertrautheit der indigenen Bevölkerung mit ihrer Umwelt sagen? Welche Stellung kommt bei ihnen der Natur im Verhältnis zur Kultur zu, ja gab es bei ihnen überhaupt eine Scheidung von Natur und Kultur? Welches sind die positiven Werte, an denen sich diese Männer und Frauen orientieren? Welches ist ihre Konzeption des Zusammenlebens? Auf all diese Fragen, die man sich aus heutiger Perspektive stellen könnte, bietet La Condamines Reisebericht keine Antwort.

Diese von negativen Zuschreibungen gekennzeichnete Passage setzt sich ungeheuer lang fort, und es ist erkenntnisreich, dass La Condamine dabei nicht nur zu der Einsicht gelangt, dass die Indianer in einem wortwörtlichen Sinne nicht bis drei zählen können, sondern dass ihnen jegliche Begrifflichkeit fehlt, die ein abstraktes Denken ermöglichen könnte. Gleichwohl bezeichnet La Condamine eine solche Fähigkeit aber als „universelle“, die mithin der gesamten Menschheit zustünde. Das ist im Grunde eine Contradictio in adjecto, denn wenn etwas universell oder universell gültig ist, dann muss es selbstverständlich auch überall gelten. Dies ist aber gerade nicht der Fall. Überdies haben sich Aussagen, dass ,Indianer` nicht bis drei zählen könnten, nachweisbar längst als falsch herausgestellt, was die Herangehensweise des ,aufgeklärten` europäischen Forschers einmal mehr in Frage stellt. 
Für das zeitgenössische europäische Publikum aber waren diese Gegenfragen allesamt Aspekte, die hinter den Kernaussagen des französischen „Académicien“ an Wichtigkeit bei weitem zurücktraten. Im französischen Universalismus sehen wir aber das Hauptverfahren am Werk, wie europäische Sitten und Gebräuche in einem ersten Schritt als universal gültig angenommen werden konnten, um in einem zweiten Schritt dann vor Ort festzustellen, dass ein bestimmtes Volk oder eine gewisse Ethnie diese universal gültigen Werte in keiner Weise beachtet oder pflegt. Ein derartiges Argumentationsmuster war im 18. Jahrhundert sehr verbreitet und zählte zu den Kernverfahren aufklärerischer Rhetorik.

Wir sehen bei Charles-Marie de La Condamine all jene Elemente ausgebreitet, die zum zentralen Streitpunkt in der für das 18. Jahrhundert zentralen Berliner Debatte um die Neue Welt werden sollten. Mit dieser Debatte werden wir uns noch ausführlich beschäftigen und deren Entstehen wie auch deren Konsequenzen diskutieren. Denn die Dumpfheit, ja Stupidität der indigenen Bevölkerung, ihre Antriebslosigkeit und Unfähigkeit, in abstrakten Begriffen zu denken, ja ihr fortgesetztes Leben in einer ewigen Kindheit, die von keinerlei Anreizen gequert wird, werden zu Kernpunkten einer Debatte, die wir uns nach diesem Ausflug zu La Condamine als aufklärerisches Diskurselement noch genauer anschauen werden.

In La Condamines Text sind mit den Bestimmungen indigener Stupidität andere Entwicklungsmöglichkeiten ausgeschieden, welche der indigenen Bevölkerung nicht (mehr) offenstehen. Dies betrifft eine Vielzahl von Entwicklungsbereichen menschlicher Kultur, die wir an dieser Stelle nicht ausführlich erörtern können. Für den Franzosen aber sind mit den beschränkten Geistesfähigkeiten auch die Möglichkeiten notwendig begrenzt, komplexere Sprachen auszubilden. Und wer weiß, wie eng das 18. Jahrhundert die Pflege der Sprache und die Ausbildung menschlicher Kognitionsmöglichkeiten zusammendachte, für den sind damit grundlegende Beschränkungen kultureller Entwicklungsfähigkeiten verbunden - also die Fähigkeiten zu eigener, selbstbestimmter Weiterentwicklung:

Alle Sprachen des südlichen Amerika, von denen ich mir einen Begriff machen konnte, sind höchst arm; mehrere davon sind energisch und fähig zur Eleganz, darunter besonders die alte Sprache Perus; aber allen fehlt es an Begriffen, um abstrakte und universelle Ideen auszudrücken; dies ist der offenkundige Beweis für die geringen Fortschritte, welche der Geist dieser Völker gemacht hat. Zeit, Dauer, Raum, Sein, Substanz, Materie, Körper, all diese Worte und viele andere besitzen kein Äquivalent in ihren Sprachen: nicht allein die Benennungen des metaphysischen Seins, sondern auch des moralischen können in ihren Sprachen nur unvollkommen und mit Hilfe langer Umschreibungen wieder- 
gegeben werden. Es gibt kein eigentliches Wort, das exakt Ausdrücke erfasst wie Tugend, Gerechtigkeit, Freiheit, Dankbarkeit, Undankbarkeit [...]. ${ }^{11}$

In diesem Zitat ist es beeindruckend, in welchem Maße Charles-Marie de La Condamine in seinen Erörterungen über die amerikanischen Sprachen das zentrale Vokabular der französischen und europäischen Aufklärung aufruft. Denn es dürfte kaum wichtigere Begriffe innerhalb der philosophischen Debatten des Siècle des Lumières geben als Raum und Zeit, die sich in der Tat im 18. Jahrhundert sehr rasch veränderten, oder auch als Materie und Körper, die vor allem im Umfeld der Debatten um die Encyclopédie künftig heiß umkämpft sein sollten. Die zweite Serie von Begriffen wie Freiheit, Gerechtigkeit oder (Un-)Dankbarkeit betrifft dabei eine eher politisch ausgerichtete Diskussion, mit der wir uns im weiteren Fortgang unserer Vorlesung noch stärker beschäftigen werden. Doch erstaunt es schon, wie kategorisch die Einschätzungen La Condamines zu den indigenen Sprachen Amerikas ausfallen. Indem der französische Gelehrte den amerikanischen Sprachen die Fähigkeit abspricht, derartige Kategorien überhaupt benennen und letztlich denken zu können, erklärt er auch deren Sprecher für unfähig, an den zentralen Auseinandersetzungen des aktuellen Geisteslebens teilzuhaben und zu den Fortschritten menschlichen Denkens Wesentliches beizutragen. Wir haben in diesen Wendungen ein höchst erfolgreiches Argumentationsmuster vor uns, wie es im Übergang zum 19. Jahrhundert und insbesondere im Umfeld der entstehenden modernen abendländischen Philologie aus einem in Entstehung begriffenen rassistischen Blickwinkel ${ }^{12}$ etwa auf nicht-flektierende Sprachen wie das Chinesische projiziert wurde. Dabei ist die linguistische Basis dieser Argumentationen - wie wir aus heutigen Forschungen wissen - mehr als fragwürdig, ist es doch keineswegs so, dass indigene amerikanische Sprachen über keinerlei Abstrakta verfügten.

Mit vergleichendem Blick auf unser voriges Zitat handelt es sich um denselben Kunstgriff, mit Hilfe dessen La Condamine nunmehr die Sprachen der Neuen Welt beurteilt und letztlich verurteilt. Denn der französische Reisende geht immer von einer europäischen Fülle aus, welcher er eine amerikanische Defizienz als scheinbaren Mangel gegenüberstellt. In diesen Formulierungen wird deutlich, wie sehr im Voyage sur l'Amazone von europäischen Begriffen

11 La Condamine, Charles-Marie de: Voyage sur l'Amazone, S. $62 \mathrm{f}$.

12 Vgl. hierzu Messling, Markus: Gebeugter Geist. Rassismus und Erkenntnis in der modernen europäischen Philologie. Göttingen: Wallstein Verlag 2016; sowie Messling, Markus / Ette, Ottmar (Hg.): Wort Macht Stamm. Rassismus und Determinismus in der Philologie (18. / 19. Jh.). Unter Mitarbeit von Philipp Krämer und Markus A. Lenz. München: Wilhelm Fink Verlag 2013. 
aus auf ein amerikanisches Nicht-Begreifen geschlossen wird. Auf eine gleichsam sprachphilosophische Manier wird auf die Existenz eines zivilisatorischen Fortschritts oder dessen Ausbleiben rückgeschlossen; ja mehr noch: Das vermeintliche Fehlen abstrakter Begriffe, das vom Reisenden einfach unterstellt wird, disqualifiziert die Sprecherinnen und Sprecher dieser Idiome als differenziert und ,fortschrittlich` denkende Menschen.

Dabei macht La Condamine mit den amerikanischen Sprachen in toto kein großes Federlesen: Sie alle werden von ihm ob ihrer Unfähigkeit, abstrakte europäische Begriffe auszudrücken, in den Orkus der Geschichte verbannt. Denn wie könnte gedacht werden, was in der amerikanischen Sprachenfamilie begrifflich überhaupt nicht vorhanden und damit denkbar ist? Dass die behaupteten ,Ausfälle“ amerikanischer Sprachen gar keine sind, haben neuere Sprachforschungen gezeigt: Aufschlussreich ist folglich vor allem, wie und auf welcher Ebene La Condamine die indigenen Sprachen und deren Sprecher abqualifiziert. Schon im Übergang zum 19. Jahrhundert sollten die Sprachforschungen eines Wilhelm von Humboldt wie seines Bruders Alexander ein gänzlich anderes Bild ergeben. ${ }^{13}$

Die umgekehrte Frage, welche amerikanischen Begriffe oder Vorstellungen in unseren europäischen Sprachen nicht vorhanden sein könnten, wird selbstverständlich nicht gestellt. Sie hätte selbstverständlich auch ein umfangreicheres Sprachstudium erforderlich gemacht, welches La Condamine gewiss nicht im Sinn hatte: Ihm ging es nur um die intellektuelle Abqualifizierung der indigenen Völker Amerikas in Gänze. Dass diese argumentative Zuspitzung aufgeklärter Stellungnahmen eines europäischen Reisenden in der zweiten Jahrhunderthälfte noch wesentlich weiter getrieben werden konnten, wird die Diskussion derartiger Positionen im vorliegenden Band unserer Vorlesungen zeigen.

Die von La Condamine in den amerikanischen Sprachen konstatierten ,Mängel' sind aus Sicht des Franzosen gravierend. Diese Feststellung bedeutet aber keineswegs, dass der Universalitätsanspruch - wie die obige Passage deutlich zeigt - aufgegeben würde. Denn die europäischen Begriffe seien selbstverständlich universaler Natur und überall gültig; erstaunlich und beeindruckend sei nur, dass sie von vielen Völkern erst gar nicht gedacht werden könnten.

13 Vgl. hierzu Trabant, Jürgen: Les frères Humboldt et les langues. In: Savoy, Bénédicte / Blankenstein, David (Hg,): Les frères Humboldt, l'Europe de l'Esprit. Paris: Editions de Monza 2014, S. 83-96; (ders.): Weltansichten. Wilhelm von Humboldts Sprachprojekt. München Verlag C.H. Beck 2012; sowie Ette, Ottmar: Wilhelm \& Alexander von Humboldt oder: Die Humboldtsche Wissenschaft. In: Spies, Paul / Tintemann, Ute / Mende, Jan (Hg.): Wilhelm und Alexander von Humboldt: Berliner Kosmos. Köln: Wienand Verlag 2020, S. 19-23. 
Doch dieses Argument ließ sich in sein Gegenteil verkehren: Gerade das Ausbleiben belege wie der Mangel an universalen Begriffen ja nur, dass diese Universalitätskriterien eben nicht erfüllt sind, weil die indigenen Völker noch nicht dieser gesetzten europäischen Universalität teilhaftig werden konnten. Mehr noch: Die amerikanischen Sprachen und damit auch die amerikanischen Völker könnten noch auf längere Zeit diesen ,universellen` Kriterien nicht entsprechen. Daher würden sie noch lange auch sprachlich in ihren Kinderschuhen stecken bleiben und keinen Anteil am Fortschritt einer universal genannten, aber französisch gedachten Menschheit haben können.

Der Voyage sur l'Amazone ist durchaus für weite Teile der Aufklärungsliteratur - insbesondere in Form des Reiseberichts - charakteristisch. Wir haben es hier mit einer der Argumentationsschleifen in La Condamines Diskurs zu tun, die verhindern, das jeweils für andere Kulturen Spezifische, das sie Auszeichnende, überhaupt zu erkennen. Das scheinbar Vor-Gewusste steuert den diskriminierenden Blick auf das ,Andere‘ und befeuert einen Alteritätsdiskurs, der - wie zumeist im europäischen Diskurs - das konstruierte Andere in seiner Fremdheit festlegt und anschließend disqualifiziert. ${ }^{14}$ Gleichzeitig bleibt der Universalitätsanspruch des Eigenen, die Setzung der eigenen Kultur zur Universalkultur, unhinterfragt und muss auch unhinterfragt bleiben, will die Superiorität Europas nicht untergraben oder zumindest teilweise in Frage gestellt werden. Wir stoßen im Voyage sur l'Amazone fraglos auf die grundlegenden diskursiven Muster, mit deren Hilfe die Europäer ihre Herrschaft über die Welt begründeten und ihre Überlegenheit legitimierten. Das Objekt dieser Untersuchungen kommt niemals selbst zu Wort, wird niemals zum eigenständigen und selbstverantwortlichen Subjekt, das seine eigene Agency besitzt, sondern verbleibt im subalternen Status des Objekts, über das zu Gericht gesessen wird.

Sehr leicht können wir an all diesen Überlegungen und Ausführungen La Condamines erkennen, dass auch und gerade der europäische Reisende selbstverständlich die Vorstellungen seiner eigenen Kultur im Gepäck mit dabei hat, dass es also nicht darum gehen kann, den Blick des Reisenden schlicht zu privilegieren und ihm eine unmittelbare, direkte Erkenntnis der Wirklichkeit zuzugestehen. Vielmehr handelt es sich um einen vorperspektivierten, von der eigenen Kultur gelenkten und bestimmten Blick, der bisweilen mehr über das

14 Vgl. zur Frage des Anderen im Zusammenhang mit der ersten Phase beschleunigter Globalisierung Todorov, Tzvetan. La conquête de l'Amérique. La question de l'autre. Paris: Seuil 1982. 
Subjekt als das Objekt dieses Blicks aussagt. Bei den interkulturellen Beziehungen liegen die Dinge vielmehr wesentlich komplizierter. Denn der Reisende führt gleichsam sein eigenkulturelles Archiv an Optionen, an Binarismen, an kulturellen Setzungen mit sich, mit dessen Hilfe das Andere zunächst einmal definiert wird, dann aber vor allem stets im Zeichen des Fehlens, des Mangels, des Nicht-Vorhandenseins in Bezug zur eigenen Kultur erscheint.

So gut wie nie erfolgt ein Blickwechsel, der die Gerichtetheit des eigenen Blicks thematisieren und in Frage stellen könnte. Wir scheiden und unterscheiden von uns den Anderen, das Andere, ohne überhaupt das behauptete Eigene zu hinterfragen und eine graduelle Diversität der verschiedenen Kulturen anzunehmen. Die Todorov'sche Zwickmühle schnappt hier wie an so vielen anderen Stellen erbarmungslos zu: In der „Question de l'autre“ versagt die europäische, die abendländische Kultur beim Versuch, das Unterschiedene nicht antinomisch, sondern komplementär zu denken. Diese abendländische Alteritätskonstruktion ist kulturell bedingt: Stets als binäre Opposition, ja als Gegner und Feind, nie aber - um es einfach auszudrücken - in Begrifflichkeiten von Yin und Yang, werden Kulturen gedacht, die voneinander differieren, voneinander verschieden sind. In westlich geformten Augen werden Kulturen meistens im Alteritätsdiskurs konstruiert, in ihrem scheinbaren Antagonismus, niemals aber in ihrer wechselseitigen und mobilen Komplementarität. Die angeführten Passagen von La Condamine zeigen auf, wie dieser abendländische Diskurs der Alterität im 18. Jahrhundert, aber auch bis zum heutigen Tage funktioniert.

All dies bedeutet letztlich, dass die ,andere“ Kultur dank ihrer ,Inferiorität“ nicht als Herausforderung für die ,eigene' Kultur erfahren wird, um deren jeweilige Optionen und epistemische Denkmöglichkeiten zu überprüfen. Die Auseinandersetzung mit dem ,Anderen“ dient vielmehr dazu, das ,Eigene“ gegenüber diesem ,Anderen' $\mathrm{zu}$ immunisieren, ihm also jene Winzigkeit zu entnehmen, die wie bei einer Impfung gespritzt werden kann, um das ,Eigene“ gänzlich unverwundbar zu machen. Die ,eigene‘ Kultur wird zur Universalkultur oder, wie man früher gesagt hätte, zur Kultur des Menschen überhaupt. Sie wird damit letztlich zur Messlatte, an der alle ,abweichenden‘ Kulturen gemessen (und für ungenügend befunden) werden können. War die Frage des Anderen - um mit Todorov zu formulieren - bereits im ausgehenden 15. Jahrhundert zentral für die abendländische Erfahrung im Umgang mit anderen Kulturen außerhalb Europas gewesen, so ist sie dies im 18. Jahrhundert auf eine noch deutlich stärkere und zugleich wesentlich ausdifferenziertere Weise. Dies insofern, als die europäische Zivilisation seit Beginn der ersten Phase beschleunigter Globalisierung einen ungeheuren ökonomischen wie intellektuellen Schub erfahren hatte. 
Daher sehen sich die Europäer selbst im Fokus und Brennpunkt aller zivilisatorischen Entwicklungslinien, ganz so, wie Friedrich Schiller in seiner Antrittsvorlesung Was ist und zu welchem Ende studiert man Universalgeschichte alle Völkerschaften um uns her, also um die normgebende europäische Kultur, gelagert sah. ${ }^{15}$ Europa musste notwendig das Entwicklungsziel, das ferne Ideal aller anderen Menschheitskulturen sein: Dies stand außer Frage! Wir werden freilich noch sehen, wie diese Gewissheiten zumindest in bestimmten aufklärerischen Kreisen langsam erschüttert wurden. Dass dies ein Prozess war und ist, dessen Notwendigkeit heute noch immer besteht, gereicht nicht gerade zum Ruhme vorgeblicher europäischer Superiorität und Überlegenheit. Doch ist immerhin die Einsicht in eine derartige Lage eine wesentliche Triebfeder dafür, die abendländische Kultur und Zivilisation immer wieder neu einem sich verändernden Umfeld anzupassen. Am Umgang mit anderen Kulturen hat sich dabei freilich nichts Wesentliches geändert.

Sie sehen: Ein globalisiertes Selbstverständnis muss nicht notwendig mit einem globalen Verstehen gekoppelt sein, sondern kann dieses sogar verhindern oder unterlaufen. Der Rückfall in ein Denken von Superiorität und Inferiorität ist im abendländischen Denken genauso angelegt wie die Umdeutung von (kultureller) Differenz und Diversität in (kulturelle) Gegnerschaft, ja Feindschaft. All dies wird gerade an dieser Passage, die eine Reihe sprachlicher Setzungen der abendländisch-europäischen Kultur und ihren Diskursuniversen scheinbar erprobt, überaus deutlich erkennbar.

Denn La Condamine gibt ja - wie bereits erwähnt - am Ende der Passage zu verstehen, dass die Indianer buchstäblich nicht bis drei zählen könnten, da ihnen selbst hierfür die Begriffe fehlten. Dies ist eine angesichts der existierenden komplexen Zahlensysteme bei unterschiedlichen indigenen Kulturen ungeheuerliche Behauptung, die ganz gewiss auch nicht damit zu rechtfertigen ist, dass der französische Reisende ja nur en passant verschiedene indigene Gruppen besucht habe. Denn dieser Reisende in Bewegung erlaubt sich pauschalisierende Einschätzungen und Urteile, die von ganz fundamentaler Bedeutung für die betroffenen Kulturen sind, ohne dass er die Grundlagen oder Bezugspunkte für seine Wertungen jemals offenlegen müsste. Wir können hieran abschätzen, wie im Gewand wissenschaftlicher Objektivität die ungerechtfertigtsten europäischen Vorurteile munter fortbestehen - auch und gerade in einer Epoche, in der vorgeblich alle Werte und Urteile einer beständigen aufklärerischen Kritik ausgesetzt sind.

15 Vgl. Schiller, Friedrich: Was ist und zu welchem Ende studiert man Universalgeschichte? Eine Akademische Antrittsrede bey Eröfnung seiner Vorlesungen gehalten von Friedrich Schiller. Professor der Philosophie in Jena. Zweite Auflage. Jena: In der Akademischen Buchhandlung 1790. 
An dieser Stelle darf ich Ihnen eine kleine Brücke vom 18. Jahrhundert über die erste Hälfte des 19. Jahrhunderts bis in die zweite Hälfte des 20. Jahrhunderts anbieten. Denn gegen eine solche Einschätzung sollte sich Alexander von Humboldt in seiner Relation historique, seinem eigentlichen Reisebericht von seiner Expedition in die amerikanischen Tropen, vehement aussprechen. Humboldt hatte im Gegensatz zu La Condamine verschiedene Zahlensysteme bei unterschiedlichen indigenen Gruppen untersucht, gerade weil er derartigen pauschalen Verurteilungen anderer Kulturen und Sprachen misstraute. In diesem Zusammenhang ist es freilich erstaunlich, dass gerade diese Passage der Rechtfertigung indigener Zahlensysteme in den späteren Ausgaben seiner sogenannten Südamerikanischen Reise so beschnitten und gekürzt wurde, dass er gleichsam dem Argument La Condamines zuzustimmen scheint. Gleichzeitig wurde die gesamte lange und ausführliche Begründung, warum die Vorstellung, dass Indianer nicht einmal bis drei zählen könnten, falsch sei, ,versehentlich“ aus seinem Text in dieser populären Ausgabe entfernt. Ein Schalk, der Böses dabei denkt! Auch dies mag ein Hinweis darauf sein, dass La Condamines Probleme bei weitem nicht nur solche des 18. Jahrhunderts sind - sie haben sehr wohl etwas mit uns und unseren Vorurteilen heute $\mathrm{zu}$ tun. ${ }^{16}$ Offenkundig erachteten die Herausgeber einer eher noch umfangreichen Edition des Humboldt'schen Reisebericht alle Bemühungen seines Verfassers für überflüssig, ausführlich zu belegen, warum derartige (und offenkundig proto-rassistische) Vorurteile wie die von La Condamine als hochgradig tendenziös und an den Haaren herbeigezogen erscheinen mussten. Es schien für die Edition erfolgversprechender, einem deutschsprachigen Lesepublikum zu suggerieren, Indianer könnten nicht bis drei zählen.

An anderen Stellen seines Voyage sur l'Amazone bemühte sich der französische Verfasser deutlicher darum, Aufklärung über einen umstrittenen Sachverhalt herzustellen. Mitten im 18. Jahrhundert, dem Jahrhundert der Aufklärung, versuchte La Condamine, Aufschluss über die Existenz von Amazonen entlang jenes Flusses zu sammeln, dem diese sagenhaften kriegerischen Frauen - freilich gänzlich unschuldig - ihren Namen gaben. Denn bekanntlich war und ist die Sage von den Amazonen, ein überaus schöner Mythos aus der griechischen Antike, der bis heute die Literatur und die Künste beflügelt und beschäftigt. Bei ihnen handelt es sich um jene wehrhaften Frauen, die keine Männer unter sich dulden, sie nur einmal pro Jahr zu sich lassen, um den weiblichen Nachwuchs zu sichern, und sich ansonsten dadurch auszeichnen, dass sie sich eine Brust

16 Vgl. hierzu Ette, Ottmar: Alexander von Humboldt und die Globalisierung. Das Mobile des Wissens. Frankfurt am Main - Leipzig: Insel Verlag 2009, S. 277-295. 
entfernen, um den Bogen besser spannen und ihre Pfeile besser abschießen zu können. Dass diese männliche Obsession gen Westen projiziert wurde, wie es ab dem beginnenden 16. Jahrhundert geschah, ist die eine Sache; dass diese Vorstellung im 18. Jahrhundert nun im wissenschaftlichen Bereich weitergesponnen wurde, eine andere. La Condamine leistet hier im Sinne Hans Blumenbergs ganze Arbeit am Mythos. ${ }^{17}$ Denn er ging mit ,wissenschaftlicher ${ }^{6}$ Methodologie jenen Gründen nach, die nach seinem Dafürhalten dazu geführt hatten, dass ähnlich wie Christoph Kolumbus in der Inselwelt der Karibik auch Orellana in den Flusslandschaften des Amazonas derartige Gruppen wehrhafter Frauen erblickt zu haben glaubte. Doch hören wir ihn selbst:

Im Verlaufe unserer Schifffahrt haben wir überall die Indianer der verschiedenen Nationen befragt und uns mit großer Sorgfalt von ihnen berichten lassen, ob sie irgend eine Kenntnis von jenen kriegerischen Frauen hätten, bezüglich derer Orellana vorgibt, sie getroffen und mit ihnen gekämpft zu haben, und ob es wahr sei, dass sie von den Männern weit entfernt lebten und diese nur einmal im Jahr zu sich ließen, wie dies Pater Acuña in seinem Bericht angibt [...]. ${ }^{18}$

Lassen Sie uns kurz auf die historischen Zusammenhänge eingehen! Als die Spanier und Portugiesen im 16. Jahrhundert den Amazonas hinauffuhren, glaubten sie in der Tat, derartige kriegerische Frauen zu erblicken. Dies war keineswegs etwas Neues, hatte ja schon Kolumbus in der Karibik vermeint, Amazonen im Meer der Antillen, der Vorinseln entdeckt zu haben. Diese Amazonen sollten nach seiner Ansicht als eigenständige Gemeinschaft auf einer separaten Insel leben, einer reinen Fraueninsel. Auch nach Kolumbus' Ansicht würden Männer nur zur Generierung von Nachwuchs zeitweise auf die Insel zugelassen. Der Mythos der Amazonen, erst einmal von der Alten auf die Neue Welt übertragen, begleitete die Entdeckungsgeschichte Amerikas jahrhundertelang. ${ }^{19}$ Die Übertragung dieses aus der griechischen Antike durch die iberischen Konquistadoren auf den südamerikanischen Kontinentalbinnenraum war auch nach der europäischen Renaissance ${ }^{20}$ durchaus dauerhaft, zumal die tropischen Regenwaldgebiete am Amazonas noch für die Forschungsbedingungen des 18. Jahrhunderts so undurchdringlich waren, dass eine leichte Überprüfung des Mythos nicht möglich war.

17 Vgl. Blumenberg, Hans: Arbeit am Mythos. Frankfurt am Main: Suhrkamp ${ }^{4} 1986$.

18 La Condamine, Charles-Marie de: Voyage sur l'Amazone, S. 84.

19 Vgl. hierzu Gewecke, Frauke: Wie die neue Welt in die alte kam. Stuttgart: Klett - Cotta 1986.

20 Vgl. Rojas-Mix, Miguel: Mito y estilo en el imaginario iberoamericano. In: Saladino, Alberto / Santana, Adalberto (Hg.): visión de América Latina. Homenaje a Leopoldo Zea. México: Instituto Panamericano de Geografía - Fondo de Cultura Económica 2003, S. 461-468. 
Charles-Marie de La Condamine wusste, was ein französisches Lesepublikum von einem Reisebericht verlangte, der eine Fahrt auf dem Amazonas zum hauptsächlichen Gegenstand hatte. Wie hätte darin nicht von den Amazonen gesprochen werden können? Daher machte sich La Condamine an die Arbeit und führte allerlei Befragungen bei den ortsansässigen Indianern entlang der von ihm gewählten Flussroute durch. Derartige Befragungen sind noch heute en vogue. Es überrascht vor diesem Hintergrund kaum, dass nahezu alle Befragten dem französischen Gelehrten gerne bestätigten, dass es solche kriegerischen Frauen in der Tat tief in den Regenwäldern verborgen gegeben habe und noch immer gebe. Ein siebzigjähriger Indianer, leider vor kurzem verstorben, solle sie noch persönlich mit eigenen Augen gesehen haben - zumindest versichert sein Sohn glaubhaft, der Vater habe noch von Angesicht zu Angesicht Amazonen gekannt. In der Kürze der Zeit konnte La Condamine nicht tiefer in die Materie eindringen, geschweige denn zu den schönen Amazonen vordringen - eine Begegnung im Regenwald, bei der es dem Franzosen gewiss nicht an galanten Einfällen gemangelt haben würde.

La Condamine berichtet, dass niemand unter den befragten AmazonasIndianern am Vorhandensein und der Existenz von Amazonen zu zweifeln schien. Wie hätten die indigenen Gruppen dies auch tun können, hatten sie doch in einer langen und für sie schmerzlichen Geschichte gelernt, dass es für sie stets am besten war, allen Gerüchten der Europäer Nahrung zu geben und ihnen den Weg zu weisen, wenn sie auf der Suche nach El Dorado, dem vergoldeten König, oder dem sagenumwobenen Schatz der Inkas waren. Die lästigen Weißen konnte man am schnellsten wieder loswerden, wenn man ihre Vorstellungen und Sehnsüchte - nach Gold und Silber, aber auch nach Sagen und Mythen - einfach bestätigte und ihnen gleich noch den Weg dorthin wies. La Condamine freilich schloss aus den verschiedenen Auskünften der von ihm an unterschiedlichen Orten befragten Indianer, dass es offensichtlich ein gemeinsames Rückzugsgebiet der Amazonen geben müsse: die Berge von Guyana, die zu den undurchdringlichsten Gebieten des südamerikanischen Binnenlandes zählten, wurden dort die Quellen des Orinoco doch erst Mitte des 20. Jahrhunderts entdeckt.

Zweifel kamen La Condamine freilich dennoch, müssten die benachbarten Indianerstämme doch, wie er in seiner Voyage sur l'Amazone festhielt, zumindest von Zeit zu Zeit Nachrichten von diesen kriegerischen Frauen geben können, von denen auch die christlichen Missionare stets berichtet hatten. Doch La Condamine, nicht unerfahren in den Windungen und Wendungen der europäischen Aufklärung, erklärte sich dies mit dem Verweis auf eine „nation ambulante“, die eben ständig ihren Wohnort wechsle. Denn es machte Sinn, sich die Amazonen nicht wie Kolumbus auf einer festen Insel, sondern als nicht-sesshafte kriegeri- 
sche Nomadinnen im Amazonas-Tiefland vorzustellen. Auch Auflösungserscheinungen zog La Condamine in Betracht: Möglich, dass sie erobert wurden, möglich aber auch, dass die Töchter den Ratschlägen der Mütter - oh heimlich-süße Hoffnung der Männer - nicht mehr länger gefolgt seien und sich nun doch wieder mit Männern dauerhaft verbunden hätten. Überflüssig hinzuzusetzen: Wir befinden uns hier im Reich der freien Spekulation, der freien Erfindung - und der Reisebericht als friktionale Gattung vermag derlei Gegenstandsbereiche, dies dürfte auch La Condamine sehr bewusst gewesen sein, hervorragend abzudecken: A beau mentir qui vient de loin ...

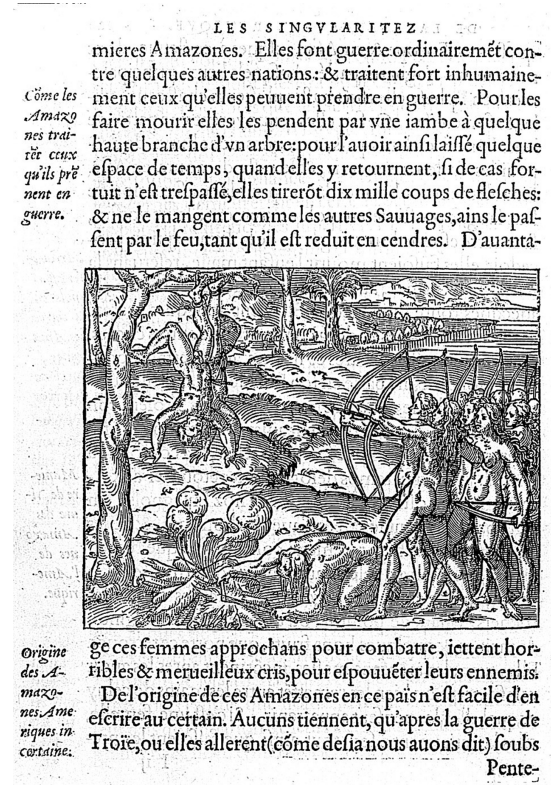

Abb. 25: Kriegerische Amazonen in Les singularitez de la France antarctique von André Thevet, 1558.

So lässt La Condamine keinen Zweifel an einer im Grunde unbezweifelbaren Tatsache: Selbst wenn man heute keine Amazonen mehr antreffen sollte, so bedeutete dies nicht, dass es niemals Amazonen am Amazonas gegeben hätte. Wer könnte gegen ein solches Argument mit guten Gründen vorgehen? Außerdem erweiterte La Condamine den Definitionsbereich des Begriffs „Amazone“ Sie wissen, wir Heutigen verstehen darunter schlicht eine Reiterin -, indem er betonte, es würde genügen, wenn diese Frauen nur einmal im Jahr Männer zu sich ließen. Sie müssten sich nicht - wie dies einst Pater Acuña berichtet 
hatte - zusätzlich noch eine Brust abgeschnitten haben. ${ }^{21}$ Es gebe Reiseberichte genug, so La Condamine, die das Vorhandensein derartiger Amazonen, freilich mit beiden Brüsten, bestätigt hätten. Der Mythos lebte fort!

Doch wir befinden uns im Jahrhundert der Aufklärung, im Siècle des Lumières, und so musste La Condamine einfach Licht in diese sagenumwobene, aber letztlich niemals aufgehellte Wissenslücke bringen. Mythenkritisch, wie die europäischen Aufklärer nun einmal waren, betonte der französische „Académicien“, dass die Indianer starrköpfig, dem Wunderbaren stets erliegend, erzählsüchtig und unglaubwürdig seien, dass aber niemand von ihnen jemals von den Amazonen des Diodorus von Sizilien gehört habe, so dass letztlich ihre Glaubwürdigkeit in diesen Dingen nicht leicht erschüttert werden könne. Und als starkes Argument könne schließlich auch die Tatsache gelten, dass sich der Amazonenmythos bei allen Indianern in Amerika finde, nicht nur bei jenen, die den tropischen Regenwald entlang der großen Ströme des Binnenlandes bevölkern. Auch die unterschiedlichsten europäischen Autoren hätten von den Amazonen gesprochen: so etwa Amerigo Vespucci, Ulrich Schmidl, Walter Raleigh und so viele mehr: La Condamine breitete sein literarisches Wissen über die Geschichte von Entdeckung und erster Kolonisierung Amerikas aus. Damit verwies er freilich auf Autoren, welche - wie wir heute wissen - nicht weniger starrköpfig, am Wunderbaren ausgerichtet und erzählsüchtig waren als jene Indianer, von denen La Condamine uns berichtete. Denn er hatte zwar bei diesen Indianern eine Umfrage gestartet, traute ihnen als Informanten aber nicht über den Weg.

Doch da gab es noch ein anderes Problem, mit dem sich in Europa das Forschungsgebiet von Amazonas und Orinoco verband, eine Frage, die gerade zum damaligen Zeitpunkt in Frankreich heiß diskutiert wurde: Die Frage einer natürlichen Flussverbindung zwischen Orinoco und Amazonas. La Condamine hatte versucht, sich auf diesem Gebiet möglichst umfassend zu informieren und zur Klärung der Frage beizutragen, ob es diese Bifurkation nun gebe oder nicht. Gesichert war: Es gab verschiedenste Hinweise darauf, dass sie über die Gabelteilung des Casiquiare liefe, von der die Zeitgenossen seit dem 17. Jahrhundert wussten. Entsprach dieses Wissen nun den Tatsachen oder war die Existenz einer Bifurkation zwischen den Flusssystemen von Orinoco und Amazonas eine Mähr?

Wir wissen heute, dass es diese berühmte Gabelteilung des Casiquiare gibt. Doch unter den französischen Zeitgenossen La Condamines war dies umstri-

21 Vgl. La Condamine, Charles-Marie de: Voyage sur l'Amazone, S. 87. 
tetn. Trotz La Condamines bestätigender Berichte wurde die Gabelteilung wenige Jahrzehnte später von einer in Frankreich überhand nehmenden sogenannten systematischen Geographie ${ }^{22}$ kurzerhand für unmöglich erklärt: $\mathrm{Zu}$ sehr war man in hierarchisierten Bezügen von Hauptfluss und Nebenflüssen gefangen, als dass man sich nicht-hierarchische netzartige Fluss-Systeme ohne weiteres hätte vorstellen können. Auch dies war ein in abendländischen Hierarchien verfangener Gedanke, der leichtfertig auf die Neue Welt übertragen wurde. So konnte nicht sein, was nicht sein durfte.

Heute wissen die meisten Studierenden der Geographie, dass es nicht notwendig ist, in die Tropen zu reisen, um eine Bifurkation zu sehen; denn auch in unseren Breiten gibt es eine Gabelteilung, nämlich die (allerdings weit weniger weltberühmte) zwischen Hase und Hunte im norddeutschen Tiefland. Man hätte es folglich auch schon im 18. Jahrhundert besser wissen können. Doch war dieses Faktum damals nicht bekannt. Als Beleg für die Existenz der Bifurkation des Casiquiare zwischen Orinoco und Amazonas führte La Condamine den Bericht einer Indianerin an, die vom Orinoco über den Río Negro bis nach Pará an der Amazonasmündung gefahren sei. ${ }^{23}$ Auch die Jesuitenoberen besuchten sich gegenseitig über diese Flussverbindung - aber konnte man denn als Aufklärer, der etwas auf sich hielt, diesen Jesuitenberichten trauen?

Für La Condamine freilich stand fest, dass man eine derartige Verbindung nicht mehr in Frage stellen konnte, auch wenn 1741 der Autor des Orinoco ilustrado, Pater Gumilla, dies noch für gänzlich unmöglich erklärt hatte. Unser französischer Reisender verwies darauf, dass die Flussverbindung sehr wohl auf den alten Karten verzeichnet gewesen sei; allein die neueren Geographen (sprich Kartographen) hätten sie auf ihren Karten unterdrückt. Eine Möglichkeit, die Sache endgültig zu entscheiden, wäre die Befahrung dieser in Frage stehenden Gabelteilung gewesen. Aber für eine so mühselige Expedition konnte La Condamine am Ende eines zehnjährigen Aufenthalts auf dem amerikanischen Kontinent keine Zeit aufwenden, war seine Flussfahrt auf dem Amazonas doch Teil seiner Rückreise von Quito nach Paris.

Doch immerhin kam auch La Condamine auf diese Weise endlich in den von allen Europäern erträumten Genuss dieses Gefühls, ein wahrer Entdecker zu sein, sei es ihm doch gelungen, trotz derlei konträrer Einschätzungen in Europa die Existenz der Flussverbindung zu belegen. Die Argumentationslinie des

22 Vgl. hierzu Broc, Numa: La Géographie des Philosophes. Géographes et voyageurs français au XVIIIe siècle. Paris: Editions Ophrys 1975.

23 Vgl. La Condamine, Charles-Marie de: Voyage sur l'Amazone, S. $92 \mathrm{f}$. 
französischen Reisenden war dabei aufschlussreich, konnte sein Reisebericht in dieser Frage doch mit einer Entdeckung aufwarten:

Die vor kurzem anerkannte Flussverbindung zwischen Orinoco und Amazonas kann umso mehr als eine Entdeckung in der Geographie gelten, als alle modernen Geographen, war auch die Vereinigung dieser beiden Ströme unmissverständlich auf den alten Karten vermerkt, diese Verbindung auf den neuen Karten gemeinschaftlich getilgt hatten und sie als Chimäre von all jenen behandelt wurde, die doch am besten über ihre Realität Bescheid wissen mussten. Es ist wohl nicht zum ersten Male, dass Wahrscheinlichkeiten und rein plausible Mutmaßungen über Fakten siegten, die doch von Reiseberichten bestätigt worden waren, so dass ein zu weit vorwärts getragener Geist der Kritik entschieden das leugnen ließ, was bestenfalls nur hätte bezweifelt werden können. ${ }^{24}$

Ganz im Geiste der Aufklärung stellte Charles-Marie de La Condamine die Frage der natürlichen Verbindung zwischen zwei riesigen Stromsystemen sehr bewusst in den Kontext der Glaubwürdigkeit und damit auch der Quellenbasis für unterschiedliche wissenschaftliche Positionen. Denn es war in der Tat eine ganz grundsätzliche Frage, um die es an dieser Stelle ging: Ließen sich die Fakten erhärten oder obsiegte der Geist einer Kritik, die nach Regeln der Wahrscheinlichkeit und Plausibilität vorging und die Fakten außer Acht ließ? Oder setzten sich vielmehr jene Positionen durch, die unabhängig von allen Wahrscheinlichkeiten auf der schieren Existenz dieser Flussgabelung beharrten?

In diesem Falle entschied sich La Condamine gegen eine alles in Frage stellende Kritik, welche alle offenen Fragen anhand eines verfügbaren Vorwissens entschied und letztlich nichts von dem glauben mochte, was als schieres Faktum in der Natur gegeben war. Der französische Mathematiker zog daraus sogar eine Kritik einer übermäßigen aufklärerischen Kritik, warnte also vor einer Kritik, die nur nach Plausibilität und Wahrscheinlichkeit entschied, nicht aber auf der Basis von Faktenwissen. Es handelt sich, wenn Sie so wollen, um die Kritik einer ins Leere laufenden Kritik, um eine Kritik an einer Kritik, die nur um der Kritik willen gegen Fakten vorging und diese in Frage stellte.

Damit wird zugleich ein zweiter Punkt berührt. Denn die Problematik der Glaubhaftigkeit von Reiseberichten wirft das seit Beginn allen Reisens vorhandene Problem einer Scheidung zwischen Reisenden und Daheimgebliebenen, zwischen den Augenzeugen und den Fabrikanten von Theorien auf, die im fernen Europa und ohne jede Kenntnis vor Ort zu beurteilen versuchten, wie es in der Realität der Kolonialländer aussehen konnte. Die Entscheidung darüber war nun wirklich keine leichte Aufgabe. An dieser Frage der Glaubwürdigkeit von Reisenden entzündete sich eine der grundlegenden Debatten, welche das

24 Ebda.. S. 93. 
18. Jahrhundert nicht nur in Europa, sondern gerade auch außerhalb Europas in eine wahre Rage versetzte. Denn es gab, wie wir ja wissen, sehr wohl eine Aufklärung auch außerhalb Europas, auch wenn diese Tatsache von Europa über einen langen Zeitraum und bis hinein in unsere Tage beständig geleugnet worden ist. Was aber, wenn diese amerikanischen Aufklärer dank ihrer Augenzeugenschaft etwas bezüglich ihrer Länder vor Ort behaupteten, was in Europa für völlig unwahrscheinlich angesehen wurde? Diese Problematik ist keineswegs als marginal zu bezeichnen: Sie stellte sich häufig und war dringlich.

Wir sehen an diesem Beispiel allerdings auch, wie sehr sich in La Condamines Reisebericht ebenfalls das Hörensagen mit Messungen und Mythen zu einer solchen Mischung verbinden, dass es schlechterdings nicht mehr möglich ist, die Theorie (oder die Konventionen) vom eigenen Sehen, von der eigenen Augenzeugenschaft zu trennen. Die so wichtige Kritik stieß hier an eine offenkundige epistemische Grenze. Dies ist nicht nur eine Frage des 18. Jahrhunderts. Denn selbstverständlich sind unsere Blicke längst kodiert, unterscheiden scheinbar Wichtiges von scheinbar Unwichtigem, ja das Richtige vom vermeintlich Unrichtigen, noch bevor wir sie auf eine uns neue Welt richten: Unsere Blicke sind stets vor-perspektiviert. Dieses Verhältnis zwischen Reisen und Schreiben wird von unserem Autor freilich nicht reflektiert: Er bewegt sich in der Neuen Welt mit einer selbstverständlichen Sicherheit des Verstehens, für das man sich die Unsicherheit und das Tastende eines Michel de Montaigne dringlich gewünscht hätte. Eine selbstkritische Überprüfung der Grundlagen eigenen Sehens und Begreifens wäre in derartigen Fällen von Nutzen gewesen. Sie sehen: Es handelt sich nicht allein um eine Frage der Wissenschaft, sondern um eine Problematik rund um deren epistemische Grundlagen! Letztlich geht es um eine philosophische Frage, mit welcher wir uns gleich beschäftigen werden.

Gerade die Reiseberichte des 18. Jahrhunderts führen uns diese Problematik in aller Deutlichkeit vor Augen. Ebenso bestätigen sie das beständige Verlangen der Europäer, in fremden Weltgegenden als Entdecker aufzutreten, also den europäischen Entdeckungsgeist gleichsam zu verkörpern und in der eigenen Figur zu personalisieren. Dies gilt auch für La Condamine, der hier von einem neuen Mesopotamien spricht und fast bruchlos auf den Mythos vom Dorado wie auch demjenigen von Manoa zu sprechen kommt, einer Stadt aus purem Gold. ${ }^{25}$ Es gibt an dieser Stelle seines Reiseberichts Wegbeschreibungen und Passagen, die zeitweise aber unter Wasser gesetzt sind, so dass alles über den Zugang zu dieser sagenhaften Stadt in der Tat an den wunderbaren Roman

25 Ebda., S. $95 \mathrm{f}$. 
Los pasos perdidos von Alejo Carpentier erinnert. Bei letzterem handelt ges sich um einen kubanischen Schriftsteller des „real maravilloso“, der sich mit der Literatur rund um den Orinoco und seine Mythen sehr gut auskannte. La Condamine freilich machte - mythenkritisch wie immer auf seine eigene Weise - einfach $\mathrm{Ab}$ striche, da vieles übertrieben worden sei: Am Grundsätzlichen mochte er jedoch nicht rütteln, sondern verwies auf die üblichen Reiseberichte. Dass daraus ein fundamentales Problem für ein gesichertes Wissens entstand, war bereits im weiteren Verlauf des Jahrhunderts der Aufklärung offensichtlich.

La Condamine hatte für seinen Reisebericht freilich eine einfache und überzeugende Struktur gewählt, wie sie für den Reisebericht, die „Relation historique“, im 18. Jahrhundert geradezu klassisch war: Er folgte seinem Itinerarium, seinem Reiseverlauf. So ging es im Bericht des Franzosen Stück für Stück den Amazonas in Richtung seiner Mündung hinunter gemäß eines natürlichen Verlaufs, in welchem ein Fluss oder Strom die Unumkehrbarkeit einer Geschichte vor Augen führt. Schließlich traf La Condamine am 19. September 1743 in Pará an der Amazonasmündung ein. Vier Monate waren seit seiner Abreise aus Cuenca im Andenhochland vergangen. An diesem Punkt seiner Reise angelangt, glaubte sich der Franzose nun bereits nach Europa versetzt, in eine Stadt mit geraden Straßen, mit Häusern aus Stein und allen Bequemlichkeiten, welche die europäische Zivilisation dem Reisenden bieten konnten. ${ }^{26}$ Er war damit zurück in einer Welt, die bald schon im Begriff stand, in eine weitere, die zweite Phase beschleunigter Globalisierung einzutreten. Die genaue Datierung deutet es an: La Condamine war wieder zurück in einem Koordinatensystem, in welchem Raum und Zeit von Europa her bestimmt waren und in welcher die zyklischen Zeitvorstellungen der Amazonas-Indianer keine Gültigkeit mehr besaßen.

Auf die Ankunft an der Mündung des Amazonas in den Atlantik folgte die Rückreise in eine französisch beherrschte Region des amerikanischen Subkontinents und damit eine etwa zweimonatige Schifffahrt von der Amazonasmündung nach Cayenne, das Ihnen zumindest als jener Ort bekannt sein dürfte, ,wo der Pfeffer wächst‘. Noch heute gibt es die Herkunftsbezeichnung „Cayenne-Pfeffer“. Die Reisenden finden sich am 26. Februar 1744 erstmals wieder in einer französischen Kolonie, wobei La Condamine als Wissenschaftler der Aufklärung auch in dieser französischen Besitzung nun noch mancherlei Versuche und Experimente durchführte, mit denen wir uns aber nicht mehr weiter beschäftigen müssen. Denn der eigentliche Voyage sur l'Amazone war abgeschlossen, die Koordinaten des größten Stromes der Amerikas waren bestimmt.

26 Ebda., S. 117. 
Je näher man an die europäische Zivilisation und deren Einflussbereich heranrückt, desto mehr rast die Zeit. In etwas mehr als sechzehn Stunden wird die Weiterreise von Cayenne zum Fluss Surinam bewerkstelligt, wo man im August 1744 ankommt. Dort geht es dann flussaufwärts weiter nach Paramaribo, der Hauptstadt der holländischen Kolonie Suriname. Von dort aus schifft man sich auf einem holländischen Kauffahrer nach Amsterdam ein, um den Atlantik zu überqueren: Längst lebten Hundertausende von Europäern in allen Teilen der Welt, um eine weltumspannende und zuverlässige Infrastruktur mit Schiffen, Häfen, Befestigungen, Forts, Lagern oder Verkaufsstellen in Gang zu halten und sicherzustellen. Im November 1744 ist man schließlich wieder im Ärmelkanal, wo das niederländische Kaufmannsschiff prompt von einem Korsaren aus Saint-Malo bedroht wird, der laut La Condamine zumindest höflicher auftritt als jener englische Korsar, der das Schiff noch vor der Küste Amerikas zu kapern gedroht hatte. Mit La Condamine lernen wir: Französische Korsaren haben wenigstens Manieren! Im Februar 1745 trifft er dann wieder in Paris ein, insgesamt fast zehn Jahre nach seiner Abreise aus der französischen Hauptstadt. An die ursprüngliche Aufgabe der Expedition, sicheres Wissen über die genaue Gestalt der Erde zu erhalten, dachte kaum noch jemand: Alle Beweise waren längst erbracht.

La Condamines Voyage sur l'Amazone wurde, wie ich schon betonte, eine sehr positive Aufnahme zuteil. Doch sein nicht minderer, vielleicht sogar größerer Ruhm ging auf eine literarische Bearbeitung seines Reiseweges durch einen Freund zurück, der ihm schon manches Mal beigestanden und seine Pläne unterstützt hatte. Lassen Sie mich also an dieser Stelle unserer Vorlesung auf einen kleinen Text verweisen, der - in einer typischen Herausgeberfiktion, wie sie für das 18. Jahrhundert so charakteristisch sind - in deutscher Sprache in Minden im Jahre des Herrn 1759 gefunden worden sein soll und von einem gewissen Voltaire unter dem Titel Candide ou l'optimisme in französischer Sprache veröffentlicht wurde. ${ }^{27}$

François-Marie Arouet, bekannter unter seinem „Nom de plume“ Voltaire, zählt sicherlich zu den herausragenden Gestalten der europäischen Aufklärung. Er wurde am 24. November 1694 in Paris geboren, wo er am 30. Mai 1778 verstarb. Von Roland Barthes in einem denkwürdigen Essay als „der letzte der

27 Voltaire: Candide ou l'optimisme. In: Romans et Contes. Texte établi sur l'édition de 1775, avec une présentation et des notes par Henri Bénac. Paris: Editions Garnier Frères 1966, S. $137-221$. 
glücklichen Schriftsteller“ bezeichnet, ${ }^{28}$ schrieb Voltaire für ein breites internationales Publikum in französischer Sprache, ebenso für den Adel wie für ein sich herausbildendes Bildungsbürgertum, mit dem er sich - und daher auch die Formulierung von Roland Barthes - vereint fühlte. Denn er war von seinem Publikum noch nicht wie die Schriftsteller des 19. Jahrhunderts und insbesondere die „Poètes maudits“ durch Abgründe getrennt, ${ }^{29}$ sondern brachte in vielerlei Hinsicht zum literarischen Ausdruck, was sein Publikum fühlte und dachte.

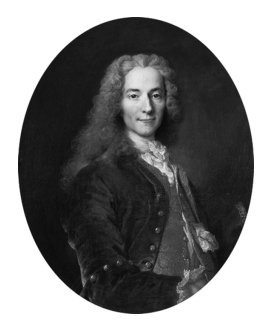

Abb. 26: Nicolas de Largillière: Voltaire (1694-1778).

In Frankreich fand Voltaire eine so starke Aufnahme, dass man bisweilen das ganze Jahrhundert nach ihm benannte und bis heute den Ausdruck „Le Siècle de Voltaire“ noch hören kann. Doch er war eine gesamteuropäische Figur; und nicht umsonst ist Voltaires Name mit Friedrich II. von Preußen und Schloss Sanssouci hier in Potsdam eng verbunden. Er gab dem Hof des Preußenkönigs für einige wenige Jahre intellektuellen Glanz und französischen Esprit. In jüngerer Zeit verbindet ein weiteres Faktum Voltaire mit unseren Potsdamer Gefilden. Wenn es auch bisweilen mit dem Argument, Voltaire sei ein Rassist gewesen wir werden gleich Passagen kennenlernen, die eine andere Sprache sprechen -, bescheidene Angriffe dagegen gab, ist der Preis für politisch verfolgte Wissenschaftlerinnen und Wissenschaftler, Völkerverständigung und kulturelle Differenz, den die Universität Potsdam jährlich vergibt, nach diesem großen Franzosen benannt. Letzterer setzte sich wie kaum ein anderer in seiner Zeit für das Recht auf freie Meinungsäußerung ein.

Der über lange Zeit außerhalb Frankreichs lebende Voltaire erreichte mit seinen literarischen und philosophischen Schriften ein breites Publikum in Europa wie auch außerhalb der Grenzen der Alten Welt, das die von ihm gegen

28 Vgl. Barthes, Roland: Le dernier des écrivains heureux. In (ders.): Essais critiques. Paris: Seuil 1964, S. 94-100.

29 Vgl. hierzu auch Ette, Ottmar: Romantik zwischen zwei Welten, S. 899-922. 
die Missstände absolutistischer Regime wie gegen die Kirche gewendeten Waffen Ironie und Sarkasmus zu schätzen wusste. Mit seinem Witz und seiner Zielsicherheit begeisterte er als Intellektueller avant la lettre insbesondere jene gesellschaftlichen Gruppen, die zu den Trägerschichten der Französischen Revolution wurden. Gegen seinen korrosiven Spott war nichts geschützt, und er legte sich mit den Mächtigen seiner Zeit an.

Doch sollte man in ihm vielleicht weniger den Wegbereiter einer Revolution, welche Voltaire für sich reklamierte, sondern den unnachgiebigen Vertreter einer Aufklärung sehen, die mit vielen gesellschaftlichen und kulturellen Tabus seiner Zeit brach. Voltaire war in seinem Leben stets bereit, sich vor dem Zugriff der Macht in ein jeweiliges Ausland zu flüchten. Das Leben richtete er, durch mehrere Gefängnisaufenthalte gewitzt, an diesen ständigen Fluchtmöglichkeiten aus. Seine Liebe zu und Verbundenheit mit Gabrielle-Emilie du Châtelet, ${ }^{30}$ die sicherlich für einen weiblichen Lebensentwurf in Wissenschaft und Philosophie des 18. Jahrhunderts stellvertretend stehen mag, ${ }^{31}$ runden ein Leben ab, das über weite Strecken im öffentlichen Rampenlicht stand. Voltaire suchte diese grenzüberschreitende Öffentlichkeit und er fand sie.

Der französische „philosophe“ war ein typischer Jesuitenschüler. Am renommierten Jesuitenkolleg Louis-le-Grand äußerte sich erstmals seine literarische Begabung, die verschiedentlich von seinen Lehrern gefördert wurde. Vom Vater zu einer juristischen Karriere gezwungen und immer wieder in seinem freidenkerischen Lebenswandel eingeschränkt, setzte sich die anfangs ebenso galante wie geschmeidige Literatenseele des stets in ,intellektuellen' Kreisen verkehrenden Voltaire durch, der bald schon mit ersten Werken und Publikationen auf sich aufmerksam machte. Doch seine geistreichen Satiren, die auch vor intimen Anspielungen nicht zurückschreckten, ließen ihn ins Gefängnis wandern, was ihn freilich nicht davon abhielt, ein insgesamt spöttisches Verhältnis zu den herrschenden Schichten des Adels zu pflegen. Die erfolgreiche und Aufsehen erregende Aufführung seines Theaterstückes EEdipe machte den Schriftsteller erstmals bei einem breiten französischen Publikum bekannt.

Nach einer erneuten Auseinandersetzung mit adeligen Auftraggebern ging Voltaire diesmal nicht in die Bastille, sondern in die Verbannung nach England, wo er sich zweieinhalb Jahre lang aufhielt und sich mit dem Denken insbesondere von John Locke vertraut machte. England wird für den aufmüpfigen

30 Vgl. etwa Du Châtelet, Gabrielle-Emilie: Discours sur le bonheur. Edition critique et commentée par Robert Mauzi. Paris 1961.

31 Vgl. hierzu Badinter, Elisabeth: Emilie, Emilie. Weiblicher Lebensentwurf im 18. Jahrhundert. München: Piper Verlag 1984. 
Franzosen auch später stets ein positiver Referenzpunkt bleiben. Wir hatten diese englische Seite Voltaires bereits in seiner Stellungnahme zugunsten der Theorien Isaac Newtons bezüglich der Gestalt der Erde kennengelernt.

Als er 1728 wieder nach Frankreich zurückkehrte, hatte er entschieden aufklärerische Schriften aus eigener Feder im Gepäck, die den bereits bekannten französischen Schriftsteller immer stärker als Philosophen der Aufklärung profilierten. Doch Voltaire wusste, dass er eine unabhängige intellektuelle Position im Frankreich des Ancien Régime nur würde bewahren können, wenn es ihm gelänge, seine finanzielle Unabhängigkeit zu sichern. Zum einen knackte er wie bereits berichtet - mit seinem Freund La Condamine die französische Lotterie, ein Reingewinn, den er - wie auch später in seinem Leben das erworbene Vermögen - geschickt anlegte; und zum anderen beteiligte er sich am Sklavenhandel, der in der damaligen ökonomischen Situation die größten Profite versprach. Er wurde damit ohne jeden Zweifel mitschuldig an einem wirtschaftlichen System, das die barbarische Ausbeutung schwarzer Menschen aus Afrika zum Gegenstand hatte, und verstrickte sich wie viele andere französische Aufklärer in Widersprüche, wie sie für diese Epoche durchaus charakteristisch waren.

Seit Juni 1733 wurde die höchst selbständige und unabhängige Emilie du Châtelet Voltaires Geliebte. Sie war eine Frau, die mit ihm auf Augenhöhe stand. Die Mathematikerin lenkte sein Interesse auf die Naturwissenschaften, zeigte sich aber auch als wichtige Gesprächspartnerin in philosophischen Dingen, war sie doch als Anhängerin von Leibniz auch eine Philosophin, die großen Einfluss auf das Denken ihres Geliebten ausübte. Voltaire freilich blieb aller Ausweitungen seiner Interessen zum Trotz ein Mann des Theaters, der regelmäßig Bühnenstücke schrieb und regelmäßig deswegen mit den staatlichen Autoritäten in Konflikt geriet. Als sich Emilie in den zehn Jahre jüngeren SaintLambert verliebte, von diesem ein Kind erwartete und im September $1749 \mathrm{im}$ Kindbett starb, war Voltaire, für den sie neben anderen Geliebten immer noch die „Amante en titre“ gewesen war, tief betroffen.

Viel ist über die Zeit Voltaires am Hofe Friedrichs II. von Preußen in Sanssouci geschrieben worden, und viel wäre über diese Zeit ab $1750 \mathrm{zu}$ berichten. Sie alle kennen das Ölgemälde Adolph von Menzels, das Voltaire in der Tafelrunde von Sanssouci zusammen mit dem König, Giacomo Casanova und weiteren illustren Gästen zeigt. Doch dieses Bild, hundert Jahre nach Voltaires Zeit am preußischen Hof gemalt, gehört in die Rubrik der Mythenbildung - und zwar der Mythen, die sich um den Preußenkönig rankten. Dass sich Friedrich der Große und Voltaire schließlich als Feinde trennten, kann nicht verbergen, dass Voltaire am Hofe dieses ,aufgeklärten“ Monarchen und preußischen Despoten, dem die Hohenzollern und manche Monarchisten in diesem Lande noch 
immer nachtrauern, viel von der Rücksichtslosigkeit beobachtete, mit der ein Staatswesen absolutistisch gelenkt werden konnte.

Die schon 1737, also noch vor dem Machtantritt Friedrichs und zu Zeiten von dessen Anti-Machiavell - auf den wir noch zurückkommen werden - begründete Freundschaft konnte über längere Zeit nicht gut gehen. Irgendwann musste es zum Bruch kommen. Es war aber wohl die Rivalität mit dem von ihm selbst Friedrich anempfohlenen Präsidenten der Berliner Akademie, Maupertuis, der einst die Expedition der Pariser „Académiciens“ nach Lappland geleitet hatte, die zur endgültigen Trennung Voltaires vom Hofe Friedrichs II. führen sollte. Voltaire ließ sich in seiner Gegnerschaft zu Maupertuis nicht mehr ruhig stellen. Was folgte, waren allerlei politische und gerichtliche Auseinandersetzungen, eine Menge Theaterdonner und später die formelle Wiederaufnahme eines offiziellen Briefwechsels zwischen Voltaire und Friedrich II., welcher freilich an die intellektuelle Intensität der Beziehung zwischen dem französischen Philosophen und dem preußischen Potentaten nicht mehr anschließen konnte.

Ich möchte mich nicht mit dem Historiker Voltaire befassen, auf den wir in dieser Vorlesung schon früher gestoßen waren und dessen Universalgeschichte heute nur noch einen eher marginalen Platz innerhalb der Literatur der Aufklärung einnimmt, sondern mich jenem kleinen Werk zuwenden, in das er Elemente der Reise seines Freundes La Condamine integrierte. Denn dieser Kurzroman gilt zu Recht als eines der großen Werke der europäischen Aufklärung und wurde zudem zu einem der größten ,Bestseller‘ des Siècle des Lumiéres.

Keineswegs kann ich an dieser Stelle auf eine detaillierte Gesamtdeutung dieses wunderschönen und wunderschön komplexen Textes zusteuern. Ich will Ihnen wohl aber bewusst machen, wie sehr im Kontext der Kritik der Leibniz'schen Philosophie die Reflexion über außereuropäische Weltregionen und Kulturen, aber auch über den außerhalb Europas von den Europäern expansiv betriebenen Kolonialismus die Literatur des 18. Jahrhunderts in Frankreich wie im Rest des alten Kontinents prägten. Daher sollten wir uns ein wenig näher ansehen, was dem arglosen Candide, der im schönen Westfalen im Schloss des Barons von Thunder-ten-tronckh erzogen wurde, nicht zuletzt auch in Amerika zustieß. Beschäftigen wir uns also mit diesem Erzähltext, der - in deutscher Sprache verfasst - nur von Voltaire herausgegeben zu sein vorgab, und beginnen wir mit dem Incipit:

In Westfalen gab es im Schloss des Herrn Baron von Thunder-ten-tronckh einen jungen Burschen, den die Natur mit den sanftesten Sitten ausgestattet hatte. Seine Physiognomie kündigte seine Seele an. Er besaß eine recht gerade Verstandeskraft, gepaart mit dem einfachsten Geiste; dies ist, so glaube ich, der Grund dafür, warum man ihn Candide nannte. Die alten Domestiken des Hauses vermuteten, dass er der Sohn der Schwester des Herrn Baron und eines guten und ehrbaren Adeligen aus der Nachbarschaft war, den dieses 
Fräulein freilich niemals heiraten wollte, weil er nur einundsiebzig Generationen an Vorfahren belegen konnte, und weil der Rest seines Stammbaumes den Wirren der Zeit zum Opfer gefallen war. ${ }^{32}$

Dies also ist der berühmte Beginn von Candide ou l'optimisme, ein Erzähltext, den Voltaire wohl bei seinem Aufenthalt in Schwetzingen verfasst haben dürfte, der alsbald von der Zensur verboten wurde - was das Werk in den Augen des Publikums nur umso lesenswerter machte - und dessen Autorschaft der französische Schriftsteller unter Angabe fadenscheiniger Gründe noch eine Zeitlang bestritt. Wir haben von Beginn eine Gegenüberstellung von Natur und Kultur, ist der Name des westfälischen Schlosses und Adelsgeschlechts doch eine witzige Verballhornung von Englisch und Französisch und steht für einen Stammbaum des Barons, in den Donner und Blitz hineingefahren seien. Auf der anderen Seite verlangt dagegen die Schwester des Barons einen ausreichend langen Stammbaum vom Vater ihres Sohnes, den dieser aber nicht beizubringen vermag. Auch wenn man im damaligen Deutschland anspruchsvoller als in Frankreich mit dem Nachweis adeliger Abstammung umging: einundsiebzig Generationen waren selbstverständlich eine sanfte Übertreibung, die insgesamt einen Adelsnachweis von mehr als zweitausend Jahren bedeutet hätten. Die Übertreibung ist ein Stilelement, das bereits im ersten Absatz dieses Kurzromans erscheint.

Candide, der Protagonist von Voltaires geistreicher Fiktion, wächst also auf einem Schlosse in Westfalen auf, wo der von der Natur bestens ausgestattete junge Mann schon vor seiner Geburt mit dem Dünkel einer Adelskultur konfrontiert wird. Auch später wird einer gütigen, zugleich aber auch ambivalenten Natur, die vom Menschen behütet und gepflegt werden muss, stets die Kultur eines Menschengeschlechts gegenüber gestellt, welche von falschen Ambitionen und Vorurteilen geprägt ist. Angesichts einer derartigen Ausgangssituation, die im Incipit bereits angedeutet wird, fällt es dem Ich, das bereits in diesem ersten Zeilen erscheint, sehr schwer, den Optimismus deutscher Aufklärungsphilosophen wie vor allem Gottfried Wilhelm Leibniz oder Christian Wolff, mit denen wir ja bereits Bekanntschaft geschlossen haben, zu übernehmen. Besonders Leibnizens Grundsatz, dass unsere Welt die beste aller möglichen Welten sei, kehrt als wiederholt lächerlich gemachtes Philosophem immer wieder auf die Textebene, auf die Bühne des Textes, zurück. Doch die Natur kann, wie Donner und Blitz im Namen des Schlosses bereits von Anfang an zeigen, zerstörerische Wirkungen zeitigen: Das Erdbeben von Lissabon, welches das Aufklärungszeit-

32 Voltaire: Candide, S. 137. 
alter buchstäblich erschütterte, dient dem Erzähler als mahnendes Beispiel. Und so bekommen auch ein Jean-Jacques Rousseau und dessen die Natur lobpreisende Jünger in diesem an Philosophemen so reichen Erzähltext ihr Fett weg und den Spott Voltaires zu spüren.

Als äußere Form wählt der spöttische Philosoph dabei die Persiflage auf den damaligen Abenteuerroman, der es mit seinen höchst unwahrscheinlichen Handlungselementen dem Schriftsteller erlaubte, auf wenigen Seiten in diesem philosophischen Kurzroman ein Höchstmaß an turbulenter Handlung zu entfalten. Der damals Frankreich, aber nicht das französische Lesepublikum meidende Autor nutzt seinen den Contes philosophiques zugerechneten Text dahingehend aus, dass er in ihm die unterschiedlichsten, im Aufklärungszeitalter ,angesagten' Themenbereiche behandelt. Auch die Romandiegese wird rasch vom marginalen Westfalen auf die gesamte Welt erweitert, wodurch sich diese Themenvielfalt bei der zeitgenössischen Leserschaft rasch mit der Welt der amerikanischen Kolonien verbindet. So hält sich Voltaires Titelheld ganz selbstverständlich - ich komme später noch auf dieses Thema zu sprechen bei den dem Jesuitenzögling nicht unbekannten Jesuiten in Paraguay auf, gilt ihr Herrschaftsbereich doch für lange Zeit als der geographisch eingrenzbare Ort einer neuen Utopie, eines neuen Gottesstaates christlicher Prägung. Ein gefundenes Fressen für einen Antiklerikalen wie Voltaire!

Die Jesuiten hatten im Landesinneren Südamerikas ein eigenes Reich, geradezu einen eigenen Staat errichtet, der keinen weltlichen Maßregelungen iberischer oder europäischer Kolonialpolitik unterlag. In diesem Staat im Staate herrschten eigene Regeln, die gleichsam von Gott höchstselbst diktiert zu sein scheinen. Doch unser Candide schaut sich aufmerksam und kritisch in diesem Jesuitenreich um und stößt auf allerlei Abscheuliches, den gesunden Menschenverstand Verletzendes. Danach folgt Voltaires Protagonist in einem „Conte“, der mit ungeheuer beschleunigten raumzeitlichen Koordinaten arbeitet, dann recht genau der Route unseres guten Amazonasforschers La Condamine, so dass Candide, wen wundert's, geradezu notwendig nach Eldorado kommen muss und damit einen der großen Mythen, die Amerika für die Europäer auch noch im 18. Jahrhundert bereit hielt, weiter zu erforschen vermag.

Bei der Annäherung an dieses Land lässt Cacambo, der Begleiter Candides, freilich keinen Zweifel daran, dass die amerikanische Hemisphäre keineswegs besser sei als die andere, also die altweltliche. ${ }^{33}$ Voltaire vermeidet alles, was die Amerikas in ein besseres Licht rücken könnte als das einheimische Europa dies war selbstverständlich schon beim Jesuitenstaat von Paraguay der Fall ge-

33 Ebda., S. $174 \mathrm{f}$. 
wesen. Und doch glaubt Candide bei seiner ersten Annäherung an das Land von Eldorado zu vermeinen, es handle sich dabei um ein besseres Land als sein Westfalen mit Minden, das er einst hinter sich gelassen hatte.

So nähert sich Candide mit seiner aufgeschlossenen Leserschaft jenem Eldorado an, das La Condamine auf seiner Reise noch verschlossen blieb. Er erfährt von einem Mann im biblischen Alter, dass dies die eigentliche Heimat der Inkas sei und dass Europa dieses Land immer wieder bedroht habe, dass letztlich aber weder die Spanier noch die Engländer mit ihrem Raleigh genauere Kenntnis über es erhalten hätten. ${ }^{34}$ Im Kontext der gattungsüblichen Übertreibungen entsteht zugleich eine derbe Kritik des europäischen Kolonialismus, wie sie deutlicher kaum hätte ausfallen können:

„Ich bin einhundertzweiundsiebzig Jahre alt und habe von meinem Herrn Vater, dem Knappen des Königs, von den erstaunlichen Revolutionen Perus erfahren, deren Augenzeuge er war. Das Königreich, in dem wir uns hier befinden, ist das ehemalige Vaterland der Inkas, die es sehr unvorsichtiger Weise verließen, um einen anderen Teil der Welt zu erobern, und so wurden sie schließlich von den Spaniern aufgerieben. Die Fürsten ihrer Familie, die in ihrem Geburtsland blieben, waren vernünftiger; in Übereinstimmung mit der ganzen Nation ordneten sie an, dass kein Bewohner jemals unser kleines Königtum verlassen dürfe; und eben dies ist es, was uns unsere Unschuld und unser Glück bewahrt hat. Die Spanier hatten eine unklare Vorstellung von diesem Lande, das sie El Dorado nannten; und ein Engländer, den man den Ritter Raleigh nennt, kam vor etwa hundert Jahren diesem Gebiet sehr nahe; da wir aber von unbesteigbaren Felsen und von Abgründen umgeben sind, haben wir bis heute stets Schutz vor der Raffgier der Nationen Europas gefunden, welche eine unbegreifliche Leidenschaft für die Steine und für den Schlamm unserer Erde besitzen, und die uns, um sich diese Güter zu verschaffen, bis auf den Letzten töten würden. “35

Zunächst ein kleines, aber bedeutungsvolles Detail: Haben Sie in diesem Diskurs des hundertzweiundsiebzigjährigen Greises bemerkt, dass die Europäer wie versessen sind auf die Steine, welche sie in diesem Königreiche vorzufinden hoffen? Nun, es waren just diese Steine gewesen, die in La Condamines Voyage sur l'Amazone doch für die Amazonas-Indianer so faszinierend waren, kannten sie doch als Bewohner des fluviatilen Tieflandes nicht die Gebirgsformationen - und damit auch die Steine - der Anden, die sich jenseits des Pongo de Manseriche auftürmten. Für die Amazonas-Indianer waren diese „cailloux“ von so ungeheurer Bedeutung, dass sie alle sofort einsammelten und wie einen Schatz horteten, bevor sie begriffen, dass es Unmengen davon geben müsse. Voltaire hatte wie wir diese Passage des Reiseberichts seines Freundes gelesen

34 Ebda., S. 178.

35 Ebda., S. $177 \mathrm{f}$. 
und das Argument nun mit Blick auf die raffgierigen Europäer umgedreht: ein schönes Beispiel für eine Intertextualität, die jedem aufmerksamen Leser von La Condamine und von Voltaire die beiderseitig starke Beziehung zwischen dem Voyage sur l'Amazone und Voltaires Candide gleichsam augenzwinkernd vor Augen führt.

Es war die Weisheit der im Lande gebliebenen Fürsten, welche die Bewohner des Landes davor bewahrte, wie andere Völker der Amerikas zu Opfern der habgierigen Europäer zu werden. Hier trifft Candide nun endlich auf ein Land, in dem es keine Mönche gibt, welche regieren, herrschen, intrigieren und all jene Leute verbrennen, die nicht ihrer Ansicht und Überzeugung sind. Die Einwohner dieses kleinen Königreiches verlassen ihren angestammten Raum nicht, überfallen keine benachbarten Nationen, gehen nicht auf Kriegszüge aus und führen keinerlei Verbrechen durch, für die sie sich vor ihren Mitmenschen verantworten müssten. Folglich glaubt sich Candide dem von ihm gesuchten und ersehnten Traumlande nahe, wo alles aufs Beste eingerichtet ist und ein glückliches Gemeinwesen besteht.

Der junge Mann glaubt sich am Ziel seiner Träume von einer besseren Welt. Hätte nur sein Lehrmeister, der Philosoph Pangloss, dieses Land gesehen, seufzt Candide, er würde nicht mehr behaupten, dass das Schloss Thunder-ten-tronckh das beste sei, was es auf Erden gebe und geben könne. Sie sehen, Voltaire spielt mit der Differenz zwischen den Reisenden und den Daheimgebliebenen, wobei er letzteren freilich das längere Ende lässt. Kein Wunder, zählte er selbst doch auch nicht zu jenen Philosophen, von denen sich Rousseau im zweiten Discours wünschte, sie würden sich auf eine Weltreise begeben. Aber mit dieser Fragestellung und Herausforderung werden wir uns noch ausführlich in unserer Vorlesung befassen, sobald wir uns intensiv mit der Berliner Debatte um die Neue Welt beschäftigen. Klar ist freilich schon jetzt, dass es Rousseau hier um ein verändertes Verhältnis von Reisen und Schreiben ging. Voltaire war seinerseits kein sehr sesshafter Philosoph: Im Gegensatz zu Immanuel Kant, der sein geliebtes Königsberg niemals verließ, hielt er sich in verschiedensten Ländern Europas auf.

Anders als sein Schöpfer Voltaire aber hatte sich Candide auf eine solche Weltreise begeben, die ihn - wie wir sahen - insbesondere nach Südamerika führte. Auf seiner Reise lernte Candide allerlei hinzu: Der Ehrgeiz treibt die Europäer vorwärts und geradewegs aus dem Glück hinaus, wie der König von El Dorado, wo es übrigens auch keine Gefangenen und Eingekerkerten gibt, sehr wohl bemerkt. $^{36}$ So reisen Cacambo und Candide - gleichsam auf den Spuren von La

36 Ebda., S. 180. 
Condamine - weiter nach Surinam, wo sie mit den Schrecken des europäischen Kolonialismus konfrontiert werden. Voltaire wählte hierfür vorsichtshalber nicht das französische Herrschaftsgebiet (und heutige Überseedepartement) Guyane, das heutzutage in Europa vor allem dafür bekannt ist, dass von dort aus die europäischen Trägerraketen für allerlei europäische Satelliten starten. Nein, er wählte vielmehr klug die holländische Kolonie, vielleicht auch um französische Empfindlichkeiten zu schonen, die einer Akzeptanz der Darstellung von Gräueltaten sowie einer beißenden Kritik hieran wohl im Wege gestanden hätten. Oder sollte auch die Tatsache, dass er Geld im französischen Sklavenhandel angelegt hatte, ein Grund dafür sein?

In jedem Fall können sich in Suriname die europäischen Reisenden der Tatsache versichern, zu welchem Preise man in Europa den ach so süßen Zucker genieße. ${ }^{37}$ Denn schnell wird klar, was hier den schwarzen Sklaven angetan wird, in welcher Weise sie unmenschlich und selbstverständlich misshandelt werden und überdies noch Hohn und Spott über sie ausgegossen wird. Voltaire ließ an dieser brutalen Ausbeutung deportierter Sklaven nicht den geringsten Zweifel und stellte alles in den drastischsten Farben dar. Nein, dies konnte nicht das von Candide auf seiner Suche nach einer besseren Welt ersehnte Land sein!

An dieser Stelle also geht der Conte philosophique unmittelbar in eine scharfe Kolonialismus-Kritik über, freilich nicht des französischen Kolonialismus, sondern vorsichtshalber des holländischen, der in Frankreich in keinem guten Rufe stand. Alle kolonialistischen Länder Europas behaupteten stets, bei ihren Nachbarn ginge es im Kolonialreich noch viel schlimmer zu. Voltaire mag seine Gründe für eine ,Schonung der französischen Sklavenausbeutung gehabt haben. Doch soll das holländische System von Sklaverei und Kolonialismus für Voltaire als pars pro toto für den europäischen Kolonialismus in seiner Gänze stehen. Und er übersetzte seine scharfe Kritik in eine Erzählhandlung von besonderer Schärfe.

So trifft Candide in Suriname auf einen schwarzen Sklaven, dem die rechte Hand und das linke Bein fehlen, der halbnackt am Boden liegt und, wie er gleich erzählen wird, von seiner Mutter aus Guinea für einige patagonische Münzen Voltaire nimmt es hier geographisch nicht so genau - in die Sklaverei verkauft worden war. Es könnte sich gleichsam um den nach Suriname verkauften Bruder von Anton Wilhelm Amo handeln, unseres schwarzen Philosophen, den ein halbes Jahrhundert zuvor die Holländer als Geschenk nach Wolfenbüttel verbrachten. Hören wir das Zeugnis dieses bedauernswerten Sklaven, der in Voltaires

37 Ebda. S. 182. 
Conte philosophique für die gesamten Gräuel der Europäer stellvertretend als Opfer steht:

Oh mein Gott!, sagte ihm Candide auf Holländisch, was tust Du da, mein Freund, in diesem schrecklichen Zustand, in welchem ich Dich sehe? - Ich warte auf meinen Besitzer, den Herrn Vanderdendur, den berühmten Händler, antwortete der Schwarze. - Ist es Herr Vanderdendur, sagte Candide, der Dich so behandelt hat? - Ja, mein Herr, sagte der Schwarze, so ist es Brauch. Man gibt uns eine Unterhose aus Tuch als einziges Kleidungsstück zweimal im Jahr. Wenn wir in den Zuckerfabriken arbeiten und uns das Schleifrad den Finger zerquetscht, dann schlägt man uns die Hand ab; wenn wir flüchten wollen, dann amputiert man uns ein Bein; beides war bei mir der Fall. Zu diesem Preise naschen Sie Zucker in Europa. ${ }^{38}$

Gewiss, Wir sind in einer Fiktion, in einem Conte philosophique, der sich der Form des literarischen Reiseberichts bedient, und nicht in einer Abhandlung mit abolitionistischem Grundton, die auf eine Abschaffung der Sklaverei abzielt. Doch deutlicher können Kolonialismus-Kritik und Verdammung der Sklaverei nicht ausfallen. Den in diesen Passagen werden Grausamkeiten aufgezeigt, die in das Jahrhundert der Aufklärung zumindest auf den ersten Blick nicht zu passen scheinen. Und doch ist es das Jahrhundert der Aufklärung, welches mit all seiner Rationalität ein Sklaverei-System kapitalistisch weiterentwickelt und noch die letzten Erträge aus den Sklaven herauspresst. Es verfeinerte also die Versklavungen früherer Jahrhunderte auf seinen Plantagen in den holländischen, englischen, französischen, spanischen oder portugiesischen Kolonien noch und passt genauestens zu diesem Siècle des Lumières mit all seiner Verfeinerung der Sitten und seiner absolutistischen Königsherrschaft.

Der kubanische Schriftsteller Alejo Carpentier sollte in seinem Roman mit dem spanischen Titel El Siglo de las Luces ${ }^{39}$ genau diesen Widerspruch zwischen der europäischen Aufklärung und dem europäischen Sklavenhandel am Beispiel der transatlantischen Beziehungen in aller Schärfe herausarbeiten. Denn es gehörte zu den Widersprüchen dieses Zeitalters, dass die Verfeinerung der Sitten mit der Verfeinerung von Sklaverei-Methoden einherging. Aber es waren Max Horkheimer und Theodor W. Adorno, die philosophisch präzise das Miteinander von Aufklärung und finsterster Despotie, von Rationalität und Unmenschlichkeit, von Kapitalismus und Lagersystem in ihrer Dialektik der Aufklärung ${ }^{40}$ herausarbeiteten. Es war in keiner Weise ein Zufall, dass die Hüttenlager schwarzer Skla-

38 Ebda.

39 Der erstmals 1962 erschienene Roman sollte in der deutschen Übersetzung 1964 leider den Surkamp-Titel Exposion in der Kathedrale erhalten.

40 Horkheimer, Max / Adorno, Theodor W.: Dialektik der Aufklärung. Philosophische Fragmente. Frankfurt am Main: S. Fischer Verlag 1986. 
ven in Südafrika oder auf Kuba zu den Vorbildern für die ersten Konzentrationslager am Ausgang des 19. Jahrhunderts in diesen spanischen beziehungsweise britischen Kolonialgebieten wurden, jenen Konzentrations- und Vernichtungslagern, die später von den deutschen Nationalsozialisten mit derselben aufgeklärten Rationalität weiter perfektioniert wurden. Und so war es auch kein Zufall, dass dieses wichtige philosophische Buch unter dem Eindruck der nationalsozialistischen Barbarei im Schatten der Konzentrationslager geschrieben wurde.

Doch zurück zu Voltaire und Candide ou l'optimisme, einem Werk, in dem der französische Philosoph bitter und kühl zugleich mit dem Optimismus Leibniz'scher Prägung abrechnete! Die Literatur wird in diesem Conte philosophique zu einem Experimentierfeld, in welchem die Möglichkeiten des Imaginierbaren und Denkbaren erprobt und in das Schreibbare umgesetzt werden, lange bevor sie in der Wirklichkeit etwa als tatsächliche politische Maßnahmen erprobt werden können. Der Literatur ist eine prospektive Funktion eigen, die auf künftige Veränderungen zielt, welche zunächst auf dem Gebiet der Fiktion durchgespielt und erprobt werden müssen. Wenn Voltaire in der gesellschaftlichen und ökonomischen Realität des 18. Jahrhunderts einen Teil seiner Mittel in den barbarischen Sklavenhandel gesteckt hatte, um Gewinne zu erzielen und seine eigene finanzielle Unabhängigkeit zu sichern, so konnte er zugleich als Schriftsteller sehr wohl jene Möglichkeiten aufleuchten lassen und literarisch durchspielen, die auf eine Überwindung dieser unmenschlichen Zustände abzielten. Dies macht Voltaire nicht zu einem Helden des Abolitionismus, wohl aber zu einem kritischen Schriftsteller, der mit den Mitteln der Literatur die gesellschaftlich gegebenen Möglichkeiten verbessern wollte. Auch in diesem Sinne lassen sich die berühmten Schlussworte Candides verstehen: „mais il faut cultiver notre jardin“ ${ }^{41}$ - konzentrieren wir uns darauf, unseren Garten zu bestellen!

Die gesellschaftliche Realität des Jahrhunderts der Aufklärung sah immer noch anders aus. Noch war die Haitianische Revolution, die Teil dieser Dialektik der Aufklärung werden sollte, Jahrzehnte entfernt. Und nicht nur Voltaire, das Mitglied der Tafelrunde Friedrichs II. von Preußen, sondern auch GuillaumeThomas Raynal, ebenfalls Besucher und Gast am Tische des Preußenkönigs in Sanssouci, besaßen realiter Aktien in diesem Zucker- und Sklavenhandelsgeschäft, das Europa, Afrika und Amerika transatlantisch zusammenband. Bei letzterem handelt es sich um die zentrale Autorfigur der Histoire philosophique et politique des établissements des Européens dans les deux Indes, der großen französischen Kolonialenzyklopädie des 18. Jahrhunderts, die mit Angriffen gegen die Sklaverei - vor allem aus der Feder Diderots - nur so gespickt war.

41 Voltaire: Candide, S. 221. 
Diese Tatsache entwertete zwar nicht die Kolonialismus-Kritik der französischen Aufklärungsphilosophen, lässt sie gleichwohl aber in einem anderen, widersprüchlicheren und komplexeren Licht erscheinen. Mit diesen Widersprüchlichkeiten einer Dialektik der Aufklärung müssen wir leben; denn letztlich sind es dieselben Widersprüche, welche noch immer die asymmetrischen Beziehungen innerhalb der aktuellen Weltwirtschaft nach der vierten Phase beschleunigter Globalisierung bestimmen.

Die Allgegenwart dieser Problematik und die Präsenz der außereuropäischen Welt in den Literaturen Europas, die an vielen anderen Beispielen der Zeit hätte aufgezeigt und belegt werden können, sei anhand dieses kleinen Beispiels, das so oft überlesen wird, einmal mehr herausgearbeitet und betont. Wir wollen uns in der unmittelbaren Fortführung unserer Vorlesung ausführlicher mit derlei Problemstellungen beschäftigen und dabei vor allem danach fragen, wie denn im Kontext des Gegensatzes zwischen Reisenden und Daheimgebliebenen und vor dem Hintergrund der zahlreichen europäischen Reiseberichte, in denen die Neue Welt behandelt wurde, das Verhältnis zwischen Alter und Neuer Welt neu angesprochen und bestimmt wurde. Dazu aber müssen wir den Titel dieser Vorlesung ernst nehmen und die Aufklärung zwischen zwei Welten aus dem Blickwinkel der Amerikas fortsetzen und näher verfolgen. 